\title{
Verb argument structure overgeneralisations for the English intransitive and transitive constructions: Grammaticality judgments, production priming and a meta-analytic synthesis
}

\begin{abstract}
We used a multi-method approach to investigate how children avoid (or retreat from) argument structure overgeneralisation errors (e.g. *You giggled me). Experiment 1 investigated how semantic and statistical constraints (preemption and entrenchment) influence children's and adults' judgments of the grammatical acceptability of 120 verbs in transitive and intransitive sentences. Experiment 2 used syntactic priming to elicit overgeneralisation errors from children (aged 5-6) to investigate whether the same constraints operate in production. For judgments, the data showed effects of semantics and statistics for all ages. This finding was confirmed by an updated meta-analytic synthesis of data from these and other constructions (which also revealed some by-construction differences). For production, only an effect of statistical preemption was observed, and only for transitivisation errors with intransitive-only verbs (e.g. *The man laughed the girl). We conclude that semantic and statistical effects are real, but are obscured by particular features of the present production task.
\end{abstract}




\section{Verb argument structure overgeneralisations for the English intransitive and transitive constructions: Grammaticality judgments, production priming and a meta-analytic synthesis}

English-learning children sometimes make errors in which they overgeneralise verbs into ungrammatical sentence structures. For example, a child may use an intransitive-only verb, such as cry, in a transitive sentence, producing an ungrammatical utterance like *You just cried me (Bowerman, 1981). These errors are called overgeneralisation errors because, while it is often appropriate to generalise a verb from one grammatical construction (e.g. intransitive - The ball rolled) to another (e.g. transitive - I rolled the ball), this process is possible with only certain verbs (so-called alternating verbs).

How children learn to restrict their generalisations to a subset of verbs is a key question in language acquisition because the answer throws light on the mechanisms by which children learn argument structure. For example, if children use entrenchment, inferring that a verb is ungrammatical in the target structure because it is used in other structures but never in that structure (Braine \& Brooks, 1995), this suggests that statistical learning mechanisms may drive the acquisition of argument structure. Alternatively, if children use the semantics of a verb to define its argument structure privileges, inferring that a verb is ungrammatical in a structure because its semantics do not overlap with those of the construction (e.g. Pinker, 1989), this implies an important role, in syntax acquisition more generally, for the learning of verb semantics. Finally, if children use preemption, inferring that a verb is ungrammatical because it is used with structures WITH SIMILAR MEANINGS to that of the target structure, but never in the target structure (Goldberg, 1995), e.g. You made me cry blocking You cried me, this implies an important role for the learning of construction-level semantics.

All three of these mechanisms - entrenchment, verb semantics and preemption - have been proposed to explain how children retreat from overgeneralisation errors, and all have some evidence to support them (e.g. Theakston, 2004; Gropen, Pinker, Hollander \& Goldberg, 1991; Brooks \& Zizak, 2002). However, it has become increasingly clear that none of these explanations can account for all of the data. For example, neither the entrenchment nor the preemption hypotheses can account for the finding that children show semanticallyconstrained argument structure preferences for completely novel verbs that have been assigned meanings either compatible or incompatible with those structures (e.g. Ambridge, Pine, Rowland \& Young, 2008; Ambridge, Pine, Rowland, Jones \& Clark, 2009; Ambridge, Pine, Rowland \& Chang, 2012; Bidgood, Ambridge, Pine \& Rowland, 2014). Conversely, the 
semantic verb class cannot explain why all of these studies also show effects of verb frequency (i.e. entrenchment and/or preemption). When taken together, these findings suggest the need for a model of how children retreat from argument-structure overgeneralisation that provides an integrated account of both semantic and statistical effects. They also suggest the need for studies that assess the relative contribution of semantic and statistical factors across a range of verbs and structures, so that the results of these studies can be used to inform the development of such a model.

Recently, our research group has started to address this problem by developing designs that pit semantic and statistical factors against each other. For example, Ambridge, Pine, Rowland, Freudenthal, and Chang (2014) used a regression design to assess the predictions of the entrenchment, semantic verb class and preemption hypotheses together against children's and adult's judgments of the acceptability of different verbs in prepositional-object (PO) and double-object (DO) datives (e.g. PO: Bart gave a present to Lisa; DO: Bart gave Lisa a present). While some verbs, like give, alternate between the two dative constructions, others are grammatical in only the PO dative (e.g. Bart said something to Lisa; *Bart said Lisa something) or the DO dative (e.g. Bart cost Homer \$5; *Bart cost $\$ 5$ to Homer)

Ambridge et al. asked participants to rate the acceptability of sentences of both types, containing PO-only, DO-only or alternating verbs. Adults completed written questionnaires, whereas children (aged 5-6 and 9-10 years) heard sentences, for a smaller set of verbs, each accompanied by an animation, and gave their judgments using a 5-point 'smiley-face' scale. These ratings constituted the outcome variable. The predictor variables were corpus-based measures reflecting the relative frequencies of the verb in dative (preemption) and other constructions (entrenchment), and a set of semantic predictors calculated from adults' ratings of each verb's semantic properties (based on Pinker, 1989). In general, this study found evidence for effects of verb semantics, entrenchment and preemption for all ages, though correlations between the entrenchment and preemption predictors meant that they could not be satisfactorily dissociated.

Ambridge, Barak, Wonnacott, Bannard, and Sala (2018) conducted a reanalysis and meta-analytic synthesis of the data from Ambridge et al. (2014) and analogous studies of the locative construction (Ambridge, Pine \& Rowland, 2012), the verbal un-prefixation construction (Ambridge, 2013; Blything, Ambridge \& Lieven, 2014) and multiple constructions (Ambridge, Bidgood, Twomey, Pine, Rowland \& Freudenthal, 2015), all of which used a similar methodology, and the same age groups. This reanalysis was designed to address a number of inconsistencies and shortcomings with regard to the original statistical 
analyses (e.g. Wurm \& Fisicaro, 2014), and to incorporate measures that more accurately operationalise entrenchment and preemption: measures of verb-bias towards/away from particular constructions, based on the chi-square statistic, rather than simple frequency. This reanalysis found that, in single-predictor models - i.e. when entrenchment and preemption are investigated independently, rather than pitted against one another - effects of all three are ubiquitous for all age groups, within each study. Furthermore, meta-analytic effects of entrenchment and preemption are observed when collapsing across studies, even using simultaneous regression models that include both predictors as well as semantic predictors (though the semantic predictors could not be included in the meta-analysis themselves, as they were highly heterogenous between constructions and studies). Within any one particular study, however, effects of entrenchment and preemption were generally (i.e. except for the un- prefixation studies) too highly correlated to allow them to be dissociated.

Although this reanalysis and meta-analysis constitutes important progress in the longrunning debate over the acquisition of restrictions on verb argument structure generalisations, two questions remain. First, do these findings extend to overgeneralisations involving the English intransitive and transitive constructions? The question is an important one, since these constructions sit at the very core of the grammar, and are more frequent by an order of magnitude than those investigated in previous studies of this type (Ambridge et al., 2015, report subtitle-corpus frequencies of $1.6 \mathrm{~m}$ and $0.4 \mathrm{~m}$ for intransitive and transitive constructions, as compared to just $0.2 \mathrm{~m}$ for the figure-locative, ground-locative, PO-dative and DO-dative combined). In the present study (Experiment 1) we answer this question by applying the methods refined in Ambridge et al. (2018) to investigate the entrenchment, preemption and verb-semantics hypotheses with regard to the English intransitive and transitive constructions. Here, errors occur when intransitive-only verbs (e.g. sing, sweat, cry) are used in the transitive construction (e.g. I'm singing him [pulling string to activate a cowshaped music box]; It always sweats me [doesn't want to wear hot sweater]; You just cried me [i.e. made me cry]; Bowerman, 1981) or vice versa (I better put it down there so it won't lose [i.e. won't get lost]; Lord, 1979). Having presented these findings, we then accordingly update the meta-analytic synthesis reported in Ambridge et al. (2018), and investigate differences between constructions.

The second question is whether the same results hold for production. This remains unaddressed by previous studies that combine entrenchment, preemption and verb semantics in a single design, all of which rely solely on grammaticality-judgment methodologies. This is an important question, since, ultimately, what we are trying to explain is how children learn 
to stop making errors in production. Nevertheless, it is very difficult to investigate semantic and statistical factors in spontaneous data since these errors are both fairly rare and potentially subject to experimenter bias (diary studies may be more likely to record the most salient errors, for example). A secondary goal of the present study is therefore to begin to develop a production methodology that can be used to investigate verb argument structure overgeneralisation errors (Experiment 2); if we are able to elicit errors, we will be able to use the frequency of these errors with different verbs to test the predictions of the entrenchment, semantics and preemption accounts in production. Our starting point is a production priming methodology that has been frequently used to investigate children's knowledge of syntax (see Branigan \& Pickering, 2017, for a review), and recently adapted to investigate morphological overgeneralisation errors (Blything et al., 2014). However, this method has not, to our knowledge, previously been used to induce verb argument structure overgeneralisation errors. Our approach, then, is to validate these production data by comparing them to comparable data observed using a judgment methodology (Experiment 1) that has been refined and verified across 16 previous studies.

\section{General Methods: Creating the predictor variables}

Before describing the individual experiments, we first outline the methods used to create the predictor variables that relate to the entrenchment, preemption and semantics hypotheses (used across the judgment and production studies).

\section{Verbs}

The test items were 40 transitive-only verbs, 40 intransitive-only verbs and 40 verbs that can alternate between the two structures (based on Pinker, 1989, and Levin, 1993). Note that these classifications were used only to select the verbs; none of the analyses use verb type as a categorical predictor, and instead use continuous measures of verb bias. Appendix A lists all of the verbs used.

\section{Frequency counts for preemption and entrenchment measures}

In order to operationalise and the predictions of the entrenchment and preemption hypotheses, verb frequency counts were taken from the British National Corpus (2007). A 
custom script (written by the fifth author) was used to obtain counts of overall uses of the relevant lexical item tagged as VERB, and to extract candidate transitives (NP VERB NP), intransitives (NP VERB), passives (NP BE VERBed/en) and periphrastic causatives (NP MAKE NP VERB). Because this process yields a large number of false positives, for each verb, a randomly selected sample of 100 transitive, 100 intransitive, 100 passive and 100 periphrastic causative uses (or if $<100$, all uses) was hand-coded (by the first author), and the count pro-rated to yield the final estimate.

The entrenchment hypothesis (e.g. Braine \& Brooks, 1995) posits an inference-from absence mechanism to explain children's retreat from overgeneralisation errors: the more a verb is heard in the input, without being heard in the ungrammatical construction, the stronger the inference that that verb-construction pairing must not be possible. Thus, the entrenchment hypothesis predicts that the more a verb has been heard REGARDLESS OF THE CONSTRUCTION, the less acceptable it will be in ungrammatical sentences, and the less likely children will be to produce an error with that verb. In most of the previous studies reviewed above, entrenchment has therefore been operationalised simply as overall verb frequency, and calculated only for so-called "non-alternating" verbs (here, intransitive-only or transitive-only verbs). However, as Ambridge et al. (2018) note, this operationalisation is problematic, because the stipulation "without being heard in the ungrammatical construction" draws an arbitrary line in the sand, ignoring the reality that grammatical acceptability is graded: few verbs are entirely unattested in a particular "ungrammatical" construction, and many verbs that are described as "alternating" between two constructions often show a bias for one over the other that is very similar to that shown by "non-alternating" verbs. Here, we therefore follow Stefanowitsch (2008) and Ambridge et al. (2018) in operationalising entrenchment using the chi-square statistic as a measure of relative bias, as explained in more detail below.

The preemption hypothesis (e.g. Goldberg, 1995), while related to the entrenchment hypothesis, adds a semantic element: the more a verb is heard in constructions with a roughly equivalent meaning to the ungrammatical construction, the stronger the inference that the ungrammatical verb-construction pairing must not be possible. Thus, the preemption hypothesis predicts that the more a verb is heard IN A COMPETING CONSTRUCTION WITH SIMILAR MEANING, the less acceptable it will be in the relevant target construction, and the less likely children will be to produce this type of error with that verb. To test this account, for intransitive utterances (e.g. *The ball kicked), we followed Brooks and Tomasello (1999) and designated the passive (e.g. The ball was kicked [by X], including both full and truncated passives) as the competing construction: like the intransitive construction, the passive 
construction puts the discourse focus on the patient by placing it first in the sentence (e.g. The plate broke; The plate was broken [by Homer]). The truncated passive also allows the sentence to exclude the agent altogether, as in the intransitive. In our corpus data, the majority of passive sentences were truncated (92.15\%). Thus, the passive uses of these verbs were very similar to intransitive uses. For transitive utterances (e.g. *The man laughed the girl), again following Brooks and Tomasello (1999), we designated the periphrastic causative (e.g. The man made the girl laugh) as the competing construction, since this construction expresses a similar meaning to the transitive, and overtly expresses both agent and patient.

As for entrenchment, the majority of previous studies reviewed above operationalised preemption using a raw-frequency measure (i.e. frequency in the grammatical construction of the pair) and ignored so-called alternating verbs. But, again, this draws an arbitrary line in the sand between dispreferred uses that are "ungrammatical", though sometimes attested, and those that are "grammatical", though attested relatively rarely. We therefore follow Stefanowitsch (2008) and Ambridge et al. (2018) in operationalising both preemption and entrenchment using the chi-square statistic as a measure of relative bias.

For preemption, the chi-square statistic reflects the extent to which the bias of a particular verb (e.g. laugh) with respect to two competing constructions (e.g. the transitive vs. the periphrastic causative: e.g. *The man laughed the girl vs. The man made the girl laugh) is similar to the bias shown by other verbs (here, the other verbs in our stimulus set) with respect to these two constructions. Unlike a version based on raw-frequency, this operationalisation of preemption allows us to calculate this measure for all verbs "alternating" and "non-alternating" alike - while taking into account the frequency of a particular verb in both the preferred and dispreferred construction of the pair. Unlike a raw frequency measure, it also factors in the base-rate of the two constructions. For example, given that the transitive is, for verbs in general, approximately 800 times more frequent than the periphrastic causative (at least in the present corpus counts), a verb like boil that is "only" 52 times more frequent in the transitive than periphrastic causative in fact shows a relatively strong bias towards the periphrastic causative. Conversely, a verb like destroy that occurs over 4,000 times in the transitive causative but never the periphrastic causative shows a strong bias for the former.

For each verb, two preemption predictors were calculated, reflecting each verb's bias (relative to all other verbs in our verb set) for (a) the transitive versus periphrastic causative construction (e.g. *The man laughed the girl vs The man made the girl laugh; Someone destroyed the city vs *Someone made the city destroy) and (b) the intransitive versus passive 
construction (e.g. *The city destroyed vs The city was destroyed; The girl laughed vs *The girl was laughed). Tables 1 and 2 illustrate the calculation of transitive-vs-periphrastic preemption predictor for laugh, and the intransitive-vs-passive preemption predictor for destroy. The Pearson chi-squared statistic (without Yates' correction) was calculated according to the standard formula below.

$\underline{(\mathrm{A} * \mathrm{D}-\mathrm{B} * \mathrm{C})^{2} *(\mathrm{~A}+\mathrm{B}+\mathrm{C}+\mathrm{D})}$

$(\mathrm{A}+\mathrm{C}) *(\mathrm{~B}+\mathrm{D}) *(\mathrm{~A}+\mathrm{B}) *(\mathrm{C}+\mathrm{D})$

Because the chi-square test is non-directional, it was necessary (as in Stefanowitsch, 2008; Ambridge et al., 2018) to set the sign of each predictor to positive (/negative) if, relative to other verbs in the set, the verb in question was biased towards (/away from) (a) the transitive (vs periphrastic) construction and (b) the intransitive (vs passive) construction. As is standard practice for frequency-based measures, the chi-square statistic was natural $\log (\mathrm{N}+1)$ transformed before its sign was assigned.

Table 1. Calculation of the transitive-vs-periphrastic preemption measure for the verb laugh.

\begin{tabular}{|l|l|l|}
\hline & \multicolumn{1}{|c|}{$\begin{array}{c}\text { transitive } \\
\text { (X VERB Y) }\end{array}$} & $\begin{array}{c}\text { Periphrastic } \\
\text { (X MAKE Y VERB) }\end{array}$ \\
\hline laugh & (A) 31 & (B) 101 \\
\hline all other verbs (summed) & (C) 477905 & (D) 483 \\
\hline
\end{tabular}

$\underline{(31 * 483-101 * 477905)^{2} *(31+101+477905+483)}=61713.26$

$(31+477905) *(101+483) *(31+101) *(477905+483)$

Natural $\log (1+61713.26)=11.03$

Preemption predictor value $=-11.03$ (bias away from transitive and towards periphrastic)

Table 2. Calculation of the intransitive-vs-passive preemption measure for the verb destroy.

\begin{tabular}{|l|l|l|}
\hline & \multicolumn{1}{|c|}{$\begin{array}{c}\text { intransitive } \\
\text { (X VERB) }\end{array}$} & $\begin{array}{c}\text { Passive } \\
\text { (X BE VERB [by Y]) }\end{array}$ \\
\hline destroy & (A) 9 & (B) 239 \\
\hline all other verbs (summed) & (C) 667300 & (D) 6176 \\
\hline
\end{tabular}

$\underline{(9 * 6176-239 * 667300)^{2} *(9+239+667300+6176)}=24012.45$

$(9+667300) *(239+6176) *(9+239) *(667300+6176)$ 
Natural $\log (1+24012.45)=10.09$

Preemption predictor value $=-10.09$ (bias away from intransitive and towards passive)

The entrenchment predictor was calculated in a similar way, though, for each verb, two different calculations were necessary: (a) entrenchment towards (+) / away from (-) the transitive construction (for use as the entrenchment predictor for trials in which this construction was rated or elicited) and (b) entrenchment towards (+) / away from (-) the intransitive construction (for trials in which this construction was rated or elicited). The major difference is that non-target uses (i.e. the two rightmost cells of the chi-square) were defined not as uses in a specific competing construction (as was the case for the preemption predictor), but rather as ALL other uses, except those already counted towards the preemption predictor. For example, when calculating (a) entrenchment towards (+) / away from (-) the transitive construction for laugh (see Table 3), we excluded the 101 periphrastic causative uses already counted towards the entrenchment predictor.

Table 3. Calculation of the transitive-sentence-target entrenchment measure for the verb laugh $(+=$ bias towards transitive, $-=$ bias away from transitive)

\begin{tabular}{|l|l|l|}
\hline & \multicolumn{1}{|c|}{$\begin{array}{c}\text { transitive } \\
\text { (X VERB Y) }\end{array}$} & $\begin{array}{c}\text { Non-transitive (excluding } \\
\text { periphrastic) } \\
\text { (e.g, X VERB) }\end{array}$ \\
\hline laugh & (A) 31 & (B) 8115 \\
\hline all other verbs (summed) & (C) 466905 & (D) 1121630 \\
\hline
\end{tabular}

$(31 * 1121630-8115 * 466905)^{2} *(31+8115+466905+1121630)=3296.20$ $(31+466905) *(8115+1121630) *(31+8115) *(466905+1121630)$

Natural $\log (1+3296.20)=8.10$

Preemption predictor value $=-8.10$ (bias away from transitive and towards non-transitive)

Table 4. Calculation of the intransitive-sentence-target entrenchment measure for the verb laugh ( $+=$ bias towards intransitive, - = bias away from intransitive)

\begin{tabular}{|l|l|l|}
\hline & \multicolumn{1}{|c|}{$\begin{array}{c}\text { intransitive } \\
\text { (X VERB Y) }\end{array}$} & $\begin{array}{c}\text { Non-intransitive (excluding } \\
\text { passive) } \\
\text { (e.g. X VERB Y) }\end{array}$ \\
\hline laugh & (A) 7173 & (B) 1074 \\
\hline all other verbs (summed) & (C) 660135 & (D) 922468 \\
\hline
\end{tabular}

$\underline{(7173 * 922468-1074 * 660135)^{2} *(7173+1074+660135+922468)}=6903.39$

$(7173+660135) *(1074+922468) *(7173+1074) *(660135+922468)$ 
Natural $\log (1+6903.39)=8.84$

Preemption predictor value $=8.84$ (bias towards intransitive and away from non-intransitive)

This decision was taken in order to ensure parity with the studies analysed in Ambridge et al. (2018), which is important for meta-analysis, and (as in this previous study) to minimise the correlation between the preemption and entrenchment measures (though, in practice they remain highly correlated, presumably because verbs that are (in/)frequent in a given construction tend to be (in/)frequent across the board). However, as a result, this predictor represents a departure from a pure entrenchment predictor (which would require calculating the predictor on the basis of all uses). Rather, it tests a specific prediction of the entrenchment hypothesis: that attested occurrences of a particular verb will contribute to the perceived ungrammaticality of attested uses, even when the two are not in competition for the same message (i.e. even when potentially-preempting uses are excluded from the calculation). That said, for the present study, the departure from a pure entrenchment predictor is negligible, since the excluded constructions (periphrastic causative and passive) are extremely infrequent relative to other uses (e.g. transitive, intransitive, single-word fragment).

\section{Semantic ratings}

Under the semantics hypothesis, verb semantics determine the permissible constructions for a particular verb, including the transitive and intransitive. The greater the overlap between the semantics of a particular verb and the semantics of the construction itself, the greater the acceptability of the resulting utterance (e.g. Pinker, 1989; Ambridge et al., 2018). Children's errors therefore reflect, at least in part, a failure to master the semantics of the verb and/or the construction, and disappear as this knowledge is refined. The approach taken by older semantics-based accounts (e.g. Pinker, 1989; Levin, 1993) was to identify discrete semantic classes of verbs that are semantically consistent with particular constructions. In line with more recent work (e.g. the studies summarised in Ambridge et al., 2018), we treated construction-consistent verb semantics as a continuum and created an objective measure of verb semantics by conducting a semantic rating task.

This raises the question of how to characterise the semantics of the English intransitive and transitive constructions. A difficulty here is that both of these constructions 
are highly semantically heterogenous. However, a general consensus (e.g. Hopper \& Thompson, 1980; Næss, 2007) is that the intransitive construction is prototypically associated with a single participant undergoing an internally-caused action (e.g. The girl laughed), while the transitive construction is prototypically associated with an event in which an agent deliberately causes an affected patient to undergo some kind of change (e.g. The girl killed the fly). We operationalised this notion of intransitive- versus transitive-consistent verb semantics by asking participants to rate verbs along Shibatani and Pardeshi's (2002) causative continuum. Applying this account to English, the main difference between semantically-intransitive and semantically-transitive verbs is the manner in which the relevant action can be caused:

For semantically-intransitive verbs (e.g. laugh), causation entails an event in which "both the causing and the caused event enjoy some degree of autonomy...The caused event... may have its own spatial and temporal profiles distinct from those of the causing event."

For semantically-transitive verbs (e.g. kill), causation “entails a spatiotemporal overlap of the causer's activity and the caused event, to the extent that the two relevant events are not clearly distinguishable" (Shibatani \& Pardeshi, 2002, p. 89)

We therefore obtained ratings for verbs on this event-merge measure. It is important to bear in mind that this measure does not capture the full range of intransitive- versus transitiveconsistent semantics in English, given the existence of, for example, transitive utterances that suggest but do not entail causation (e.g. The man kicked the ball), and those that do not denote causation at all (e.g. Food costs money). At the same time, given the general agreement regarding the PROTOTYPICAL semantics of these constructions, we anticipated that this event-merge measure would serve as a reasonable approximation of intransitive- and transitive-consistent verb semantics (and, indeed, the present findings bear this out).

\section{Participants}

The participants for this semantic rating task were 20 adults aged 18-25, all undergraduate students at the University of Liverpool. They were each paid $£ 10$ for their participation. All participants were monolingual speakers of English, and had no known language impairments. They did not take part in the other experiments reported in this paper. The test items were the 120 verbs chosen for use in the main studies (see Appendix A). 


\begin{abstract}
Method
Participants rated each verb on this event-merge measure on a visual analogue scale, presented using PsychoPy 2.0 (Pierce, 2009). Participants were told:

You will see 120 videos in which a PERSON/THING carries out/undergoes an ACTION/EVENT/CHANGE. This ACTION/EVENT/CHANGE is caused by another PERSON/THING.
\end{abstract}

An animation (created using Anime Studio Pro 5.5) was then shown (in each case, one of the same animations used in the subsequent judgment and production studies), accompanied by the following text (at the top of the screen)

Here, A (the CAUSER) causes B (the PERSON/THING) to carry out/undergo an ACTION/EVENT/CHANGE. We are interested in the extent to which A causing the ACTION/EVENT/CHANGE and B undergoing the ACTION/EVENT/CHANGE are separate. Please rate the extent to which...

Displayed below the animation was a single visual analogue scale with the following anchors:

(Left) B's ACTION/EVENT/CHANGE and A's causing of it are two separate events, that could happen at different times and/or in different points in space.

(Right) B's ACTION/EVENT/CHANGE and A's causing of it merge into a single event that happens at a single time and a single point in space

The participant clicked on the scale to make her judgment. This procedure was repeated for all 120 trials (presented in random order). The semantic rating for each verb was created simply by taking the mean rating (converted into a 100-point scale) across all participants.

The entrenchment, preemption and semantic rating measures described above were used as predictor variables in the judgment and production studies described below.

\title{
Experiment 1: Grammaticality judgments with adults and children
}




\title{
Method
}

Participants. The participants were 96 children aged 5-6 years old (5;3-6;5, $M=5 ; 10)$, 96 children aged 9-10 years old (9;4-10;6, M=9;11), and 24 adults aged 18-25 years old. Four times as many children as adults were required (in each age group) as each child completed only $1 / 4$ of the total number of adult trials). The children were recruited from primary schools in the North West of England. The adults were all undergraduate students at the University of Liverpool, and received course credit for their participation. All participants were monolingual speakers of English, and had no known language impairments.

Test items. For each of the 120 verbs, transitive and intransitive sentences were created as follows:

\author{
Marge/Bart/Lisa/Homer [VERBed] the [object/person/animal] [modifying phrase] \\ E.g. Lisa dropped the ball to the floor \\ The [object/person/animal] [VERBed] [modifying phrase] \\ E.g. The ball dropped to the floor
}

The arguments of the intransitive and transitive sentence for each verb were always matched in this way. The transitive and intransitive sentences for each verb were recorded by the final author, a native speaker of British English. Identical animations (the same as those used for the semantic rating task) were used for the transitive and intransitive versions of each sentence. The use of animations ensured that the veracity of the sentences would not be in doubt and, therefore, that participants' judgments would be based on the grammaticality of the sentences only, something that we have previously found to be important when testing young children (e.g. Ambridge et al., 2008).

Procedure. Test sentences and their accompanying animations were presented to participants using VLC Media Player. Grammaticality judgments were given on a 5-point SMILEY-FACE judgment scale (see e.g. Ambridge et al., 2008), shown in Figure 1.

\section{INSERT HERE}

Figure 1. The smiley face scale used by adult and child participants to rate sentences for grammatical acceptability. Reprinted from Cognition, 106(1), Ambridge, B., Pine, J.M., Rowland, C.F. \& Young, C.R. (2008) The effect of verb semantic class and verb frequency 
(entrenchment) on children's and adults' graded judgements of argument-structure overgeneralisation errors, 87-129, Copyright (2008), with permission from Elsevier.

Adults watched the full set of animations, in a pseudo-random order such that no two sentences containing the same verb were presented consecutively, in small groups of up to 10 participants. Adults marked their responses (individually) on an answer sheet containing one smiley-face scale for each sentence. Due to constraints on attention span, children were tested individually on one quarter of the sentences each (60 in total), split over two days. Each child was tested on transitive and intransitive versions of sentences containing 10 each of transitive-only, intransitive-only and alternating verbs. Sentences were again presented in a pseudo-random order. Children gave their responses by placing a green or red counter (indicating broadly grammatical or broadly ungrammatical, respectively) onto a single, larger smiley-face scale. The experimenter noted down responses by hand.

\section{Results and Discussion}

Following Ambridge et al. (2018), we conducted three sets of analyses with dependent variables of (a) ratings for transitive sentences, (b) ratings for intransitive sentences and (c) by-participant difference scores reflecting preference for intransitive over transitive uses (i.e. $\mathrm{b}$ minus a). The relationship between the continuous preemption, entrenchment and verb semantic measures and ratings for transitive and intransitive sentences are plotted in Figures 2-4, and for difference scores in Figures 5-7. Results were analysed in RStudio (version 1.1.442; $\mathrm{R}$ version 3.4.4, $\mathrm{R}$ Core Team, 2018). The predictor variables were the continuous preemption, entrenchment and verb-semantic measures, scaled into SD units and centred at zero, to allow for comparison with the previous datasets reanalysed in Ambridge et al. (2018).

INSERT HERE

Figure 2. Relationship between preemption and judgments of transitive and intransitive sentences (raw scores)

Figure 3. Relationship between entrenchment and judgments of transitive and intransitive sentences (raw scores)

Figure 4. Relationship between verb semantics and judgments of transitive and intransitive sentences (raw scores)

Figure 5. Relationship between preemption and transitive-minus-intransitive difference scores 


\title{
Figure 6. Relationship between entrenchment and transitive-minus-intransitive difference scores \\ Figure 7. Relationship between verb semantics and transitive-minus-intransitive difference scores
}

\author{
A high degree of collinearity between the preemption and entrenchment predictors \\ was observed: $r=0.71, r=0.74$ and $r=0.86$ for the datasets containing ratings of transitive \\ sentences, intransitive sentences, and difference scores respectively. As in Ambridge et al. \\ (2008), we address this collinearity in two ways. First, in addition to simultaneous mixed \\ effects regression models (lme4 package version 1.1-14, Bates, Maechler, Bolker \& Walker, \\ 2017), we also report single-predictor models. Second, we do not report final models (since \\ the coefficients of individual predictors in simultaneous models are misleading under \\ collinearity) but only the outcome of likelihood ratio tests comparing a full model to a model \\ with the predictor of interest removed (Barr, Levy, Scheepers \& Tily, 2013), implemented \\ using the dropl command of the lme 4 package. Since this test is non-directional, the direction \\ of each effect is inferred from the single-predictor model (a changed direction between \\ single-predictor and simultaneous models is not interpretable in the event of collinearity). We \\ also follow Barr et al. (2013) in employing random intercepts for participant and item, and \\ by-participant random slopes for the predictor variables, following a stepwise removal \\ procedure in the event of convergence failure. We first report separate analyses by age group, \\ and subsequently investigate developmental trends with a final set of models that include age \\ group and its interactions with each of the predictor variables. \\ For the single-predictor models (see Table 5), all with maximal random effects \\ structure, all three predictors were significant, with large chi-square values, for all ages (5-6, \\ 9-10, adults), and all sentence types (transitives, intransitives, difference scores). This echoes \\ the pattern reported by Ambridge et al. (2018) for the locative, dative, and various \\ constructions. \\ For the simultaneous models (see Table 6), it was not possible to use fully maximal \\ random effects structure, but, following Ambridge et al. (2018), we achieved near-maximal \\ converging models that were identical in structure for all age groups simply by disallowing \\ correlations between random effects (using the DOUBLE BAR lme4 syntax), for example:

$$
\begin{aligned}
& \text { Participant })+(1 \mid \text { Verb })+\text { PRE_FOR_TRN }+ \text { ENT_FOR_TRN + Semantics, } \\
& \text { data }=\text { subset(TRN, AgeGroup=="Age5"), REML=F })
\end{aligned}
$$$$
\text { Age5TRN }=\text { lmer }(\text { Rating } \sim(1+\text { PRE_FOR_TRN+ENT_FOR_TRN+Semantics } \|
$$ 


$$
\text { drop1(Age5TRN, test = "Chisq") }
$$

Compared with the single-predictor models, the ubiquitous effect of verb semantics remained across all simultaneous models, but effects of preemption and entrenchment played off against one another, such that, at most, one or the other - never both - was significant in a particular model. However, it is important to emphasise that, given the high degree of collinearity between these predictors, one should not attempt to interpret the pattern of significant and non-significant preemption and entrenchment effects across models and age groups.

Finally, we conducted a developmental analysis to investigate whether, as suggested by Figures 2-7, the observed effects of preemption, entrenchment and semantics increase with age. Because simultaneous models are difficult to interpret given collinearity, this was done for single-predictor models only. The model comparison method (e.g. Barr et al., 2013) was used to determine whether adding the interaction of the relevant predictor with age improved coverage of the relevant single predictor model. This was found to be the case for preemption, entrenchment and semantics (see rightmost columns of Table 5). However, caution is required here, because it is impossible to tell whether this developmental pattern reflects genuine increased effects of preemption, entrenchment and verb semantics with age (as would be predicted by these theories), or simply improved performance on the judgment task itself.

In summary, for all ages, for judgments of transitives, intransitives and difference scores, the data show effects of semantics and statistics (preemption or entrenchment, but we cannot say which, due to collinearity). This exactly mirrors the pattern observed by Ambridge et al. (2018) for the locative, dative and various constructions. 
Table 5. Judgment study: Single-predictor models

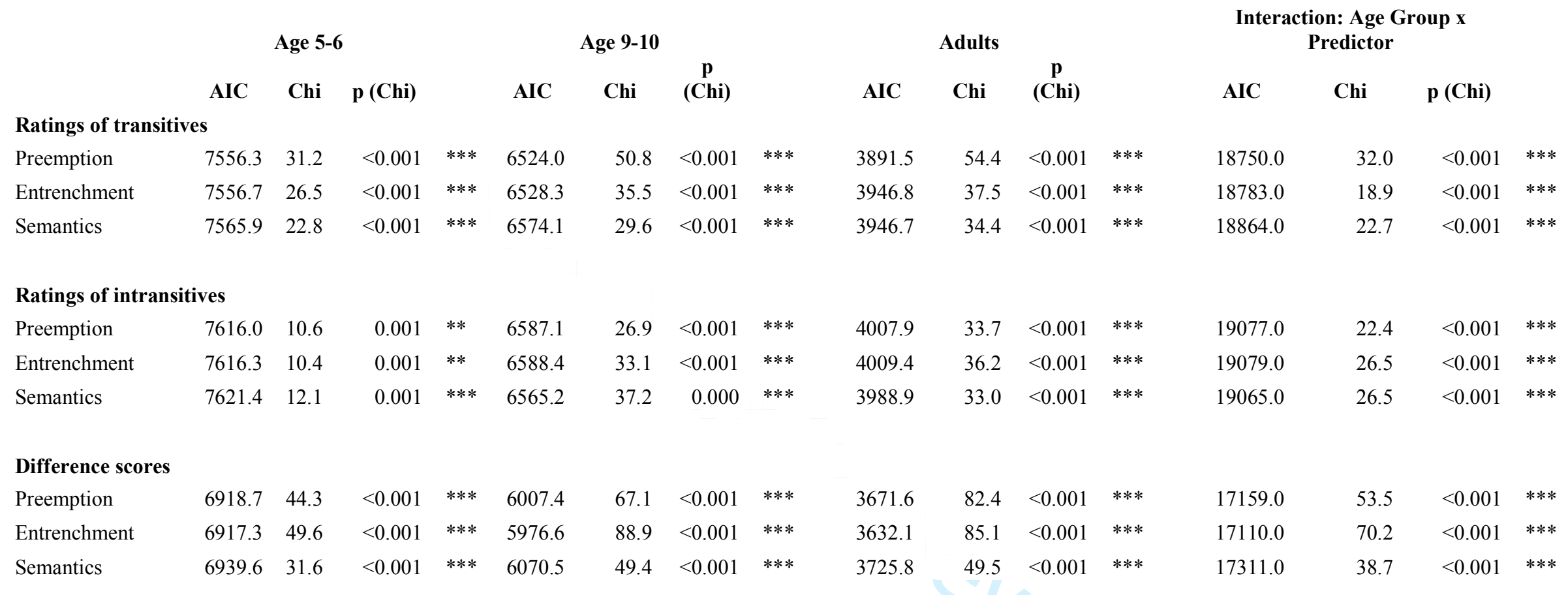


Table 6. Judgment study: Simultaneous (multiple-predictor) models

\begin{tabular}{|c|c|c|c|c|c|c|c|c|c|c|c|c|}
\hline \multirow{3}{*}{ Ratings of transitives } & \multicolumn{3}{|c|}{ Age 5-6 } & \multicolumn{5}{|c|}{ Age 9-10 } & \multicolumn{4}{|c|}{ Adults } \\
\hline & AIC & Chi & \multicolumn{2}{|l|}{ p (Chi) } & AIC & Chi & \multicolumn{2}{|l|}{$\underset{\text { (Chi) }}{\mathbf{p}}$} & AIC & \multirow[t]{2}{*}{ Chi } & \multicolumn{2}{|l|}{$\underset{(\mathbf{C h i})}{\mathbf{p}}$} \\
\hline & & & & & & & & & & & & \\
\hline Preemption & 7525.3 & 5.4 & 0.021 & $*$ & 6462.3 & 13.6 & $<0.001$ & $* * *$ & 3849.2 & 15.0 & $<0.001$ & $* * *$ \\
\hline Entrenchment & 7522.4 & 2.4 & 0.121 & & 6450.6 & 1.9 & 0.171 & & 3835.8 & 1.6 & 0.209 & \\
\hline Semantics & 7525.7 & 5.7 & 0.017 & $*$ & 6456.0 & 7.2 & 0.007 & $* *$ & 3844.1 & 9.9 & 0.002 & $* *$ \\
\hline \multicolumn{13}{|c|}{ Ratings of intransitives } \\
\hline Preemption & 7604.2 & 1.7 & 0.193 & & 6503.2 & 2.4 & 0.121 & & 3936.5 & 5.1 & 0.024 & * \\
\hline Entrenchment & 7602.8 & 0.3 & 0.593 & & 6503.8 & 3.0 & 0.085 & . & 3933.9 & 2.6 & 0.108 & \\
\hline Semantics & 7607.8 & 5.2 & 0.022 & $*$ & 6519.4 & 18.6 & $<0.001$ & $* * *$ & 3945.8 & 14.4 & $<0.001$ & $* * *$ \\
\hline \multicolumn{13}{|c|}{ Difference scores } \\
\hline Preemption & 6866.1 & 1.7 & 0.198 & & 5847.6 & 0.5 & 0.459 & & 3518.9 & 2.7 & 0.100 & . \\
\hline Entrenchment & 6869.7 & 5.2 & 0.022 & $*$ & 5866.0 & 19.0 & $<0.001$ & $* * *$ & 3533.6 & 17.4 & $<0.001$ & $* * *$ \\
\hline Semantics & 6874.1 & 9.6 & 0.002 & $* *$ & 5866.4 & 19.4 & $<0.001$ & $* * *$ & 3534.5 & 18.2 & $<0.001$ & $* * *$ \\
\hline
\end{tabular}




\section{Meta-analytic synthesis}

Method. Given that the present judgment study used the same age groups, methods and operationalisations of preemption and entrenchment as the studies summarised in the meta-analytic synthesis reported in Ambridge et al. (2018), it is important to update this synthesis to reflect these new findings (semantic predictors are not included, since these are highly heterogenous between studies). An additional goal was to consider differences between constructions and age groups with regard to the size of the observed effects of preemption and entrenchment, which we did by including these factors as potential moderators in meta-regression models.

Except for the addition of the new datasets, the method used was identical to that reported in Ambridge et al. (2018), to which the reader is referred for a full description. As for this previous analysis, we used the software package Comprehensive Meta-Analysis (www.meta-analysis.com) to generate, as our measure of effect size, an $r$ value based on the $p$ value from the likelihood ratio (chi-square) tests reported in Tables 4-5. It would not have been appropriate, as is more conventional in meta-analysis, to have used measures from nonpartial or simultaneous models (e.g. the Beta value for each predictor), given the observed collinearity between the entrenchment and preemption predictors, and given the importance of obtaining an effect size measure for preemption ABOVE AND BEYOND entrenchment, and vice versa. These $r$ scores were converted into Fisher's $Z$ values, and an estimate of variance calculated on the basis of the sample size (in participants), as per the following equations:

$$
\begin{aligned}
& Z=\frac{1}{2} \ln \frac{1+r}{1-r} \\
& V_{z}=\frac{1}{N-3}
\end{aligned}
$$

where $r$ is the correlation coefficient and $N$ is the number of participants (Schmidt \& Hunter, 2015). Meta-analytic multi-level models (Konstantopoulos, 2011; REML estimator, Knapp \& Hartung's [2003] adjustment) were built for (a) Preemption, raw scores, (b) Entrenchment, raw scores; (c) Preemption, difference scores, and (d) Entrenchment difference scores. For all four of these measures, we calculated the overall effect size ( $\bar{Z}$; intercept models) and investigated the role of construction and age group as potential moderators (meta-regression 
models). All models were built using the Metafor package (Viechtbauer, 2010) for R, as per the following example syntax:

Intercept models (raw- and difference scores): $\operatorname{rma} \cdot \operatorname{mv}(\mathrm{z}, \mathrm{var}, \operatorname{random}=\sim 1$ | Study)

Meta-regression models (raw scores): $\operatorname{rma} \cdot \operatorname{mv}(\mathrm{z}$, var, $\operatorname{mods}=\sim$ Construction + AgeGroup, random $=\sim 1 \mid$ Study)

Meta-regression models (difference scores): $\operatorname{rma} \cdot \operatorname{mv}(\mathrm{z}$, var, mods $=\sim$ AgeGroup, random $=\sim 1 \mid$ Study)

where $z$ is the Fisher $Z$ value described above and the cluster is the Study (i.e., the construction pair), with six levels: (1) figure/ground locative (Ambridge et al, 2011), (2) DO/PO-dative (Ambridge et al, 2014), (3) various constructions (Ambridge et al, 2015), (4) un-prefixation (Ambridge, 2013; Blything et al, 2014), (5) un-prefixation extended replication (adults only; Ambridge et al, 2018), and (6) transitives/intransitives (i.e. the present judgment study). For the difference score analyses, Age Group, but not Construction, was included as a moderator, since each difference score relates not to a single construction, but a pair of constructions, identified by the Study cluster.

\section{INSERT HERE}

Figure 8. Forest plot of meta-analytic synthesis for preemption (raw scores) Figure 9. Forest plot of meta-analytic synthesis for entrenchment (raw scores)

Results. In the raw-scores analysis (see Figures 8-9), both preemption $(\bar{Z}=0.36, S E=$ $0.11, k=25, p<.001)$ and entrenchment $(\bar{Z}=0.20, S E=0.03, k=25, p<.0001)$ were significant. While, the preemption intercept model showed some between-cluster (i.e. study) variance and true heterogeneity (i.e. heterogeneity not due to random error) $\left(\sigma^{2}=0.06 ; Q(24)\right.$ $=96.80, p<.0001)$, no such variance was found in the entrenchment intercept model $\left(\sigma^{2}=\right.$ $0.00 ; Q(24)=22.58, p=.54$ ). In the preemption meta-regression model (Table 7), the test of moderators was significant $(Q M(9)=22.96, p=.006)$, while the test of residual heterogeneity was not $(Q M(15)=20.37, p=.16)$. Similarly, in the entrenchment meta-regression model (Table 8), the test of moderators was significant $(Q M(9)=17.23, p=.045)$, and the test of residual heterogeneity was not $(Q M(15)=5.35, p=.989)$. This pattern indicates that true heterogeneity between different datasets (i.e. heterogeneity not due to random error) was 
virtually absent for entrenchment, and, for preemption, was accounted for almost entirely by the moderators, Age Group and Construction.

Table 7. Meta-regression model for preemption (raw scores)

Note: Reference categories $=$ DO-Dative, Adults

\begin{tabular}{lcccccccc}
\multicolumn{1}{c}{ Factor } & $Z$ & $S E$ & z.val & \multicolumn{1}{c}{$p$} & 95 CI lower & 95 CI upper & \\
\hline Intercept & 0.29 & 0.20 & 1.43 & 0.153 & -0.11 & 0.69 & \\
Figure_Locative & 0.65 & 0.28 & 2.37 & 0.018 & 0.11 & 1.19 & $*$ \\
Ground_Locative & 0.54 & 0.28 & 1.98 & 0.048 & 0.00 & 1.08 & $*$ \\
Intransitive & 0.05 & 0.27 & 0.20 & 0.839 & -0.47 & 0.58 & \\
PO_Dative & -0.14 & 0.15 & -0.93 & 0.350 & -0.42 & 0.15 & \\
Transitive & 0.24 & 0.27 & 0.90 & 0.368 & -0.28 & 0.77 & \\
Un_Verb & 0.27 & 0.25 & 1.06 & 0.289 & -0.23 & 0.76 & \\
Various & -0.04 & 0.27 & -0.16 & 0.873 & -0.57 & 0.48 & \\
Age5_6 & -0.24 & 0.08 & -2.90 & 0.004 & -0.39 & -0.08 & $* *$ \\
Age9_10 & -0.13 & 0.08 & -1.57 & 0.117 & -0.29 & 0.03 &
\end{tabular}

Table 8. Meta-regression model for entrenchment (raw scores)

Note: Reference categories $=$ DO-Dative, Adults

\begin{tabular}{lcccccccc}
\multicolumn{1}{c}{ Factor } & $Z$ & $S E$ & z.val & $p$ & 95 CI lower & 95 CI upper & \\
\hline Intercept & 0.41 & 0.12 & 3.57 & $<0.001$ & 0.19 & 0.64 & $* * *$ \\
Figure_Locative & 0.11 & 0.14 & 0.82 & 0.413 & -0.16 & 0.39 & \\
Ground_Locative & -0.25 & 0.14 & -1.79 & 0.074 & -0.52 & 0.02 &. \\
Intransitive & -0.16 & 0.13 & -1.26 & 0.208 & -0.40 & 0.09 & \\
PO_Dative & -0.29 & 0.15 & -1.99 & 0.047 & -0.58 & 0.00 & $*$ \\
Transitive & -0.14 & 0.13 & -1.08 & 0.282 & -0.38 & 0.11 & \\
Un_Verb & -0.09 & 0.14 & -0.65 & 0.515 & -0.37 & 0.19 & \\
Various & -0.08 & 0.12 & -0.68 & 0.498 & -0.33 & 0.16 & \\
Age5_6 & -0.13 & 0.08 & -1.66 & 0.097 & -0.29 & 0.02 &. \\
Age9_10 & -0.12 & 0.08 & -1.53 & 0.126 & -0.28 & 0.03 &
\end{tabular}

In order to investigate further the effects of these moderators, we calculated meta-analytic effect sizes by construction and age group, and conducted Tukey post-hoc comparisons, with Holm's $p$-value correction for multiple comparisons (see Tables 9-12).

Table 9. Preemption effect sizes by construction (raw scores) 
95 CI lower 95 CI upper

\begin{tabular}{lrrrrrrr}
\hline Figure_Locative & 0.80 & 0.09 & 8.69 & $<0.001$ & 0.62 & 0.98 & $* * *$ \\
Ground_Locative & 0.70 & 0.09 & 7.53 & $<0.001$ & 0.51 & 0.88 & $* * *$ \\
Un_Verb & 0.48 & 0.09 & 5.09 & $<0.001$ & 0.30 & 0.67 & $* * *$ \\
Transitive & 0.37 & 0.07 & 5.33 & $<0.001$ & 0.23 & 0.51 & $* * *$ \\
Intransitive & 0.18 & 0.07 & 2.63 & 0.008 & 0.05 & 0.32 & $* *$ \\
DO_Dative & 0.16 & 0.10 & 1.57 & 0.116 & -0.04 & 0.37 & 0.26 \\
Various & 0.13 & 0.07 & 1.84 & 0.066 & -0.01 & -0.18 & 0.23
\end{tabular}

\begin{tabular}{|c|c|c|c|c|c|c|}
\hline \multicolumn{2}{|c|}{ Comparison } & $Z$ & $S E$ & z.val & $p$ & \\
\hline Figure_Locative & - DO_Dative & 0.64 & 0.14 & 4.61 & $<0.001$ & $* * *$ \\
\hline Ground_Locative & - DO_Dative & 0.53 & 0.14 & 3.84 & 0.003 & $* *$ \\
\hline Intransitive & - DO_Dative & 0.02 & 0.12 & 0.16 & 1.000 & \\
\hline PO_Dative & - DO_Dative & -0.14 & 0.15 & -0.94 & 1.000 & \\
\hline Transitive & - DO_Dative & 0.21 & 0.12 & 1.66 & 0.967 & \\
\hline Un_Verb & - DO_Dative & 0.32 & 0.14 & 2.27 & 0.278 & \\
\hline Various & - DO_Dative & -0.03 & 0.12 & -0.28 & 1.000 & \\
\hline Ground_Locative & - Figure_Locative & -0.11 & 0.13 & -0.82 & 1.000 & \\
\hline Intransitive & - Figure_Locative & -0.62 & 0.12 & -5.37 & $<0.001$ & $* * *$ \\
\hline PO_Dative & - Figure_Locative & -0.78 & 0.14 & -5.60 & $<0.001$ & $* * *$ \\
\hline Transitive & - Figure_Locative & -0.43 & 0.12 & -3.75 & 0.004 & $* *$ \\
\hline Un_Verb & - Figure_Locative & -0.32 & 0.13 & -2.44 & 0.192 & \\
\hline Various & - Figure_Locative & -0.68 & 0.12 & -5.84 & 0.000 & $* * *$ \\
\hline Intransitive & - Ground_Locative & -0.51 & 0.12 & -4.44 & $<0.001$ & $* * *$ \\
\hline PO_Dative & - Ground_Locative & -0.67 & 0.14 & -4.83 & $<0.001$ & $* * *$ \\
\hline Transitive & - Ground_Locative & -0.33 & 0.12 & -2.82 & 0.082 & . \\
\hline Un_Verb & - Ground_Locative & -0.21 & 0.13 & -1.62 & 0.967 & \\
\hline Various & - Ground_Locative & -0.57 & 0.12 & -4.91 & $<0.001$ & $* * *$ \\
\hline PO_Dative & - Intransitive & -0.16 & 0.12 & -1.26 & 1.000 & \\
\hline Transitive & - Intransitive & 0.19 & 0.10 & 1.90 & 0.627 & \\
\hline Un_Verb & - Intransitive & 0.30 & 0.12 & 2.54 & 0.165 & \\
\hline Various & - Intransitive & -0.06 & 0.10 & -0.56 & 1.000 & \\
\hline Transitive & - PO_Dative & 0.34 & 0.12 & 2.76 & 0.093 & . \\
\hline Un_Verb & - PO_Dative & 0.46 & 0.14 & 3.25 & 0.022 & $*$ \\
\hline Various & - PO_Dative & 0.10 & 0.12 & 0.82 & 1.000 & \\
\hline Un_Verb & - Transitive & 0.11 & 0.12 & 0.95 & 1.000 & \\
\hline Various & - Transitive & -0.24 & 0.10 & -2.47 & 0.192 & \\
\hline Various & - Un_Verb & -0.35 & 0.12 & -3.01 & 0.046 & $*$ \\
\hline
\end{tabular}

Table 10. Preemption effect sizes by age group (raw scores) 


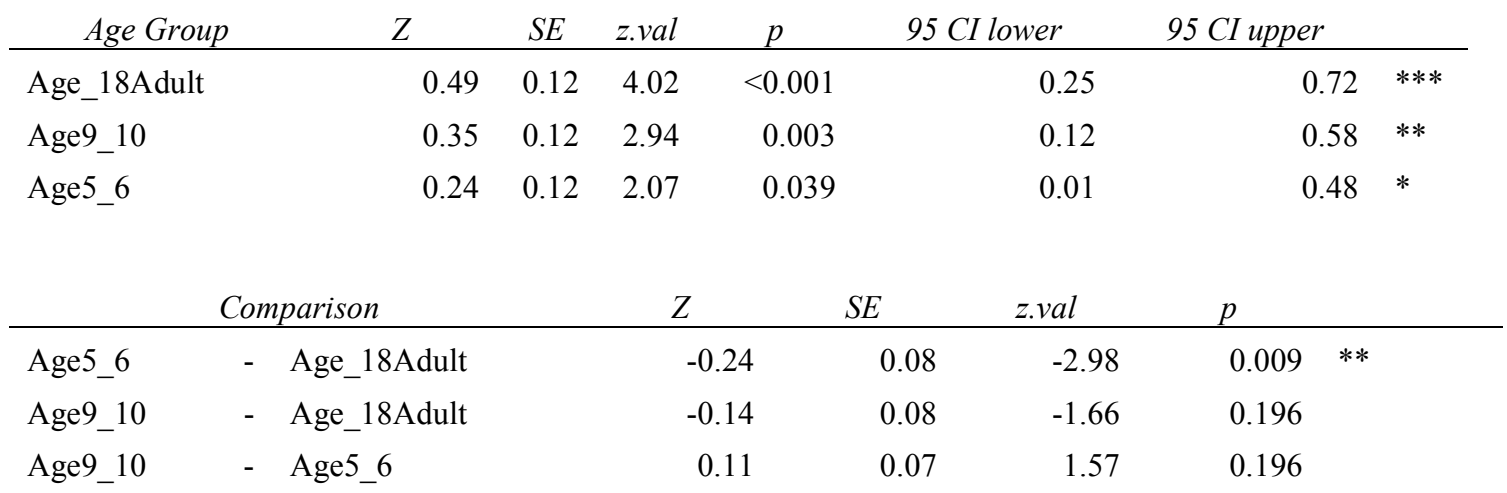

Table 11. Entrenchment effect sizes by construction (raw scores)

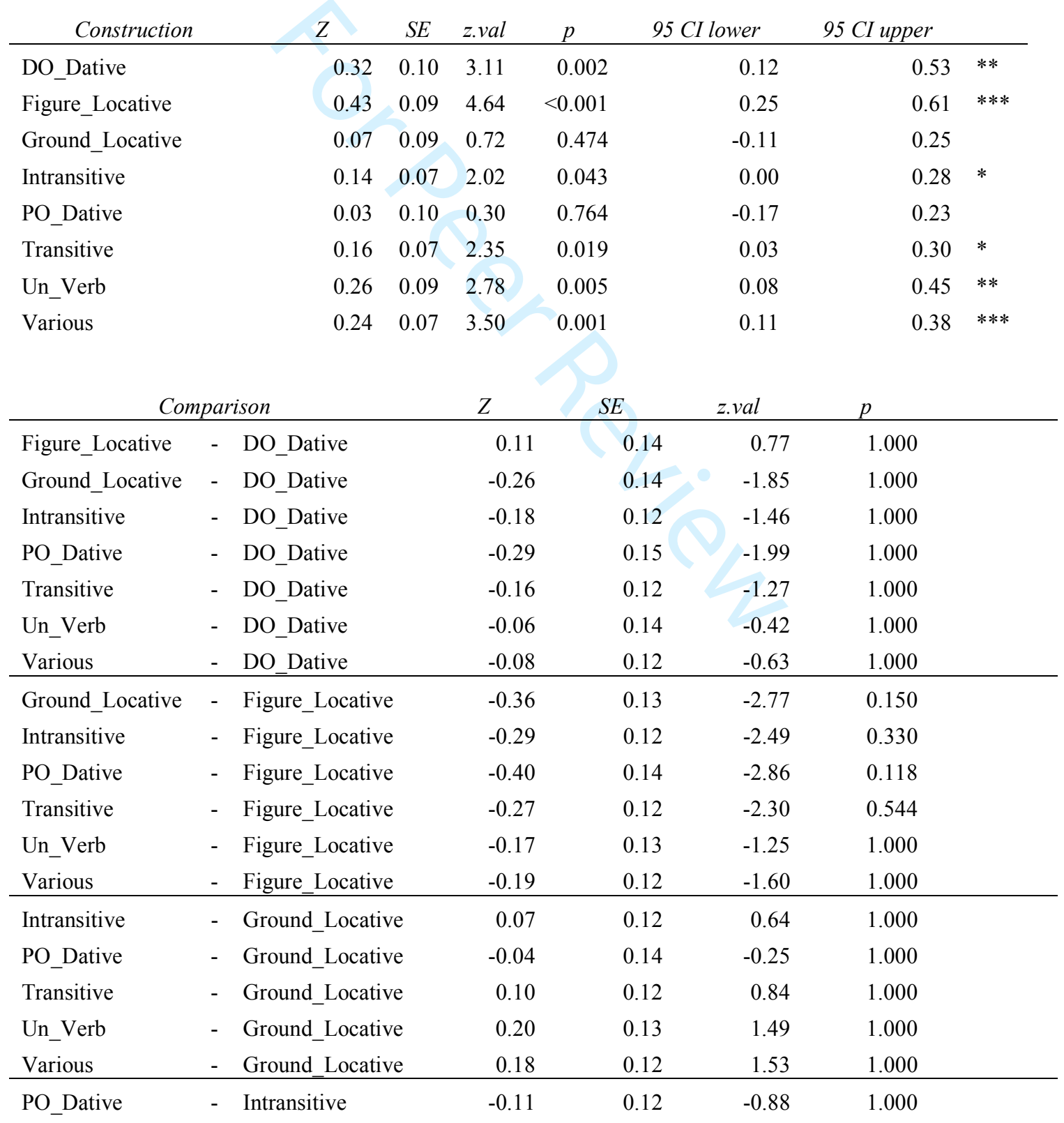


Table 12. Entrenchment effect sizes by age group (raw scores)

\begin{tabular}{lccccccc}
\multicolumn{1}{c}{ Age Group } & $Z$ & $S E$ & z.val & $p$ & 95 CI lower & 95 CI upper \\
\hline Age_18Adult & 0.31 & 0.06 & 5.18 & $<0.001$ & 0.19 & 0.43 & $* * *$ \\
Age9_10 & 0.17 & 0.05 & 3.54 & $<0.001$ & 0.08 & 0.27 & $* * *$ \\
Age5_6 & 0.17 & 0.05 & 3.49 & $<0.001$ & 0.07 & $0.26 * * *$
\end{tabular}

\begin{tabular}{|c|c|c|c|c|c|}
\hline & Comparison & $Z$ & $S E$ & z.val & $p$ \\
\hline Age5_6 & - Age_18Adult & -0.14 & 0.08 & -1.89 & 0.180 \\
\hline Age9_10 & - Age_18Adult & -0.14 & 0.08 & -1.79 & 0.180 \\
\hline Age9_10 & - Age5_6 & 0.01 & 0.07 & 0.10 & 0.920 \\
\hline
\end{tabular}

In general, effects of both preemption and entrenchment were observed for each individual construction (including intransitives and transitives) when collapsing across age group, and vice versa. However, preemption was not significant for the PO-dative, DO-dative or various constructions, while entrenchment was not significant for the PO-dative and ground locative constructions. That said, it would be unwise to place a high degree of confidence in apparent differences between constructions, given that each construction pair was tested in a different study, with different experimenters, participant populations (e.g. different schools) and other uncontrolled factors. Furthermore, because the $p$ values used to calculate the effect sizes measure for preemption after controlling for entrenchment, and vice versa, effect sizes for a particular construction are negatively related to the degree of collinearity between the two predictors. To the extent that these comparisons are interpretable, for preemption, the transitive and intransitive constructions appear to be in the middle of the effect size range. Both show a smaller effect than for the figure locative, and the intransitive also shows a smaller effect than for the ground locative, but no other comparisons involving the transitive and intransitive constructions were significant. For 
entrenchment, no by-construction comparisons were significant, which is to be expected given the almost complete absence of between-cluster variance and between-sample heterogeneity in the meta-regression model.

With regard to age, although, numerically, effects of both preemption and entrenchment appear to increase with development, the only significant comparison is between the youngest (5-6 years) and oldest participants (adults) for preemption. Although this pattern is consistent with the preemption hypothesis - on the basis that the effect would be expected to build up with repeated exposure - it is also consistent with the possibility that older participants are simply better able to complete the judgment task.

\section{INSERT HERE}

Figure 10. Forest plot of meta-analytic synthesis for preemption (difference scores) Figure 11. Forest plot of meta-analytic synthesis for entrenchment (difference scores)

In the difference-scores analysis (see Figures 10-11), both preemption $(\bar{Z}=0.29, S E=0.06, k$ $=16, p<.0001)$ and entrenchment $(\bar{Z}=0.32, S E=0.06, k=16, p<.0001)$ were again significant. Both intercept models showed a low degree of between-cluster variance $\left(\sigma^{2}=\right.$ 0.01 and $\left.\sigma^{2}=0.01\right)$, and a non-significant amount of true heterogeneity $(Q(15)=21.78, p=$ .11 and $Q(15)=22.18, p=.10$, respectively). The meta-regression analysis of difference scores included only the age moderator because construction pair perfectly overlapped with the cluster (i.e. study). The analysis (Tables 13-14) showed that the test of this moderator was significant for preemption $(Q M(2)=6.68, p=.04)$ but not entrenchment $(Q M(2)=3.13, p=$ $.21)$. The test of residual heterogeneity was not significant in either model $(Q E(13)=14.20, p$ $=.36$ and $Q E(13)=19.75, p=.10)$. This pattern indicates that heterogeneity was low for both preemption and entrenchment and, for the former, largely explained by age-related differences.

Table 13. Meta-regression model for preemption (difference scores) Note: Reference category $=$ Adults

\begin{tabular}{lrrrrrr}
\multicolumn{1}{c}{ Factor } & \multicolumn{1}{c}{ SE } & z.val & \multicolumn{1}{c}{$p$} & 95 CI lower & 95 CI upper \\
\hline Intercept & 0.42 & 0.08 & 5.38 & $<0.001$ & 0.27 & 0.58 \\
Age5_6 & -0.24 & 0.10 & -2.58 & 0.010 & -0.43 & -0.06 \\
Age9_10 & -0.16 & 0.10 & -1.66 & 0.096 & -0.35 & 0.03
\end{tabular}

Table 14. Meta-regression model for entrenchment (difference scores) 


\begin{tabular}{lrrrrrr}
\multicolumn{1}{c}{ Factor } & \multicolumn{1}{c}{ Z } & \multicolumn{1}{c}{ z.val } & \multicolumn{1}{c}{$p$} & 95 CI lower & 95 CI upper \\
\hline Intercept & 0.38 & 0.09 & 4.49 & $<0.001$ & 0.22 & 0.55 \\
Age5_6 & -0.15 & 0.10 & -1.59 & 0.113 & -0.34 & 0.04 \\
Age9_10 & -0.03 & 0.10 & -0.31 & 0.753 & -0.22 & 0.16
\end{tabular}

In order to further investigate this apparent developmental effect, we calculated meta-analytic effect sizes broken down by age, and computed Tukey-Holm comparisons (see Tables 1516).

Table 15. Preemption effect sizes by age group (difference scores)

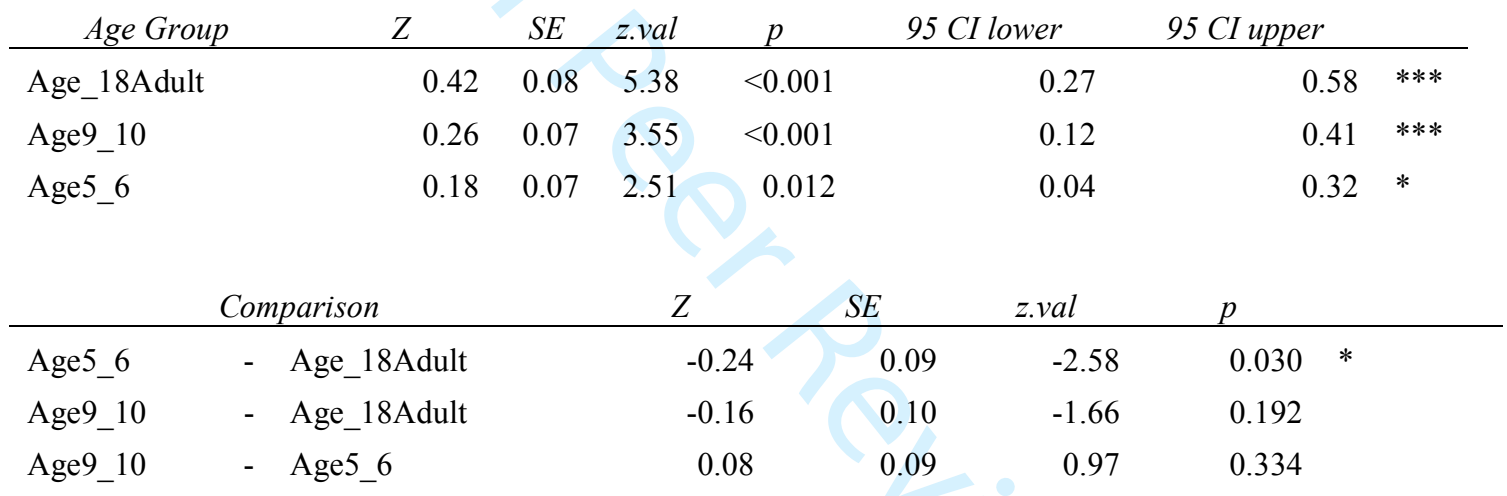

Table 16. Entrenchment effect sizes by age group (difference scores)

\begin{tabular}{lccccccc}
\multicolumn{1}{r}{ Age Group } & $Z$ & SE & z.val & $p$ & 95 CI lower & 95 CI upper \\
\hline Age_18Adult & 0.38 & 0.09 & 4.49 & $<0.001$ & 0.22 & $0.55 * * *$ \\
Age9_10 & 0.35 & 0.08 & 4.31 & $<0.001$ & 0.19 & $0.51 * * *$ \\
Age5_6 & 0.23 & 0.08 & 2.91 & 0.004 & 0.08 & $0.38 * *$
\end{tabular}

\begin{tabular}{|c|c|c|c|c|c|}
\hline & Comparison & $Z$ & $S E$ & z.val & $p$ \\
\hline Age5_6 & - Age_18Adult & -0.15 & 0.10 & -1.59 & 0.340 \\
\hline Age9_10 & - Age_18Adult & -0.03 & 0.10 & -0.31 & 0.750 \\
\hline Age9_10 & - Age5_6 & 0.12 & 0.09 & 1.40 & 0.340 \\
\hline
\end{tabular}

As for the corresponding raw-scores analysis, although, numerically, effects of both preemption and entrenchment appear to increase with development, the only significant 
comparison is between the youngest (5-6 years) and oldest participants (adults) for preemption; again a pattern that is consistent with the account, but also with a task-based explanation.

In summary, despite the by-construction and by-age differences observed for preemption, the updated meta-analytic synthesis confirms that, whether we analyse raw or difference- scores, effects of both preemption and entrenchment are observed (a) for the intransitive and transitive constructions investigated in the present study, (b) for most other constructions previously investigated, (c) for all age-groups studied and (d) when aggregating across all individual datapoints using meta-analytic techniques.

\section{Experiment 2: Production-priming in five- to six-year-old children}

In Experiment 2, we used a priming methodology to attempt to elicit verb argument structure overgeneralisation errors from five- to six-year-old children. Because this method has not, to our knowledge, been previously used to induce such errors, it requires validation. This will be accomplished by comparing the findings to those observed in Experiment 1, which used a paradigm (grammaticality judgments) that is well established in this domain.

\section{Method}

Participants. The participants were 64 children aged 5-6 years old $(5 ; 2-6 ; 4, M=5 ; 8)$ recruited from primary schools in the North West of England. All were monolingual speakers of English and had no known language impairments. None of these children had participated in Experiment 1.

Materials. Test items were the same as in Experiment 1, with the addition of a single alternating verb (float, produced by the experimenter only), added for the purposes of the bingo game described below. The 120 verbs used in Experiment 1 (40 each of transitive-only, intransitive-only and alternating verbs, according to their Pinker/Levin classifications) were split into four sets, each containing 20 alternating verbs and 10 each of the transitive-only and intransitive-only verbs. Alternating verbs were therefore used twice as many times in total as fixed-transitivity verbs, since they were used in both priming conditions. Each child received a single verb set for their target verbs. The experimenter used 20 each of the remaining nonalternating verbs for the prime sentences. 
Procedure. The aim of this experiment was to encourage children to produce both intransitivisation errors with transitive-only verbs (e.g. * The ball kicked; cf. Homer kicked the ball) and transitivisation errors with intransitive-only verbs (e.g. *Homer swam the fish; $c f$. The fish swam). In order to do so, we used a production-priming methodology in which an experimenter produced (a) grammatical intransitive sentences to encourage the child to produce intransitivisation errors with transitive-only verbs and, on a separate day, (b) grammatical transitive sentences to encourage the child to produce transitivisation errors with intransitive-only verbs. In order to encourage use of the target verb, a second experimenter gave both the child and the first experimenter 'clue words' to help them describe the animation. Examples of trials in each prime condition are given below, with the target error we were attempting to elicit.

\section{(a) Intransitive prime condition (transitive-only target verbs)}

Experimenter 2 (clue words): lightbulb, glow

Experimenter 1: The lightbulb glowed

Experimenter 2 (clue words): ball, hit

Child: *The ball hit

\section{(1) Transitive prime condition (intransitive-only target verbs)}

Experimenter 2 (clue words): lift, bag

Experimenter 1: Bart lifted the bag

Experimenter 2 (clue words): wait, boy

Child: *Lisa waited the boy

Each child participated on two occasions, on separate days. In each session, children took turns with an experimenter to describe a series of animations. These animations were presented using Processing (www.processing.org). Both experimenter and child were given 'clue words' by a second experimenter to encourage them to use the intended verb. The clue words consisted of the verb followed by the direct object, when transitive sentences were being primed, or the subject followed by the verb, when intransitive sentences were being primed. The second experimenter noted down children's responses, although all sessions were also audio-recorded using Audacity in order to check responses later if there was any doubt about what the child had said. 
Half of the children received transitive primes on the first day and intransitive primes on the second, and vice versa for the other children. The first three pairs of animations were training trials containing only transitive-only or intransitive-only verbs for both experimenter and child, whichever the child was to be primed with on that day. These verbs were not in the child's verb set, nor were they used as primes by the experimenter in that child's test trials. Twenty test trials then followed, with the experimenter continuing to use transitive-only or intransitive-only verbs, depending on prime condition. The experimenter produced only grammatical sentences. In contrast, half of the target verbs given to the children were alternating verbs (and would therefore be grammatical whether the child produced a transitive or an intransitive sentence) and half were transitive-only or intransitive-only, whichever was the OPPOSITE of the prime condition. For these trials, if the child produced a sentence using the same construction as that with which they had been primed, an overgeneralisation error would result.

In order to motivate the children to produce the sentences, a BINGO GAME was used (as in Rowland, Chang, Ambridge, Pine \& Lieven, 2012). Each time Experimenter 1 or the child produced a sentence, Experimenter 2 (who could not see the computer screen) looked for a matching bingo card. In fact, Experimenter 2 had all of the bingo cards and whether or not the card was given to Experimenter 1/the child was predetermined: the games were fixed so that the child always won both games on the first day, lost the first game on the second day (in order to maintain tension) and then won the final game. This manipulation required an extra trial for Experimenter 1 only, on Day 2, always with the (alternating) verb float. Each bingo game lasted for ten trials, in order to keep the child's attention and motivation.

\section{Results}

Children's responses were coded for sentence type: transitive (active), intransitive, passive (full or truncated), periphrastic causative, other use of the verb, excluded (target verb not included/no response). As we are investigating overgeneralisations, the errors of interest were intransitive uses of transitive-only verbs and transitive uses of intransitive-only verbs. Sentences were included in the analysis only if the child used the target verb in his/her response, with error rate calculated as a proportion of errors from the total number of responses that included the target verb. Replacement of NPs with pronouns or generic terms was allowed (e.g. the dad hit the ball for Homer hit the ball; it fell for the cup fell), as were changes in tense/aspect (e.g. Homer hit/hits/was hitting the ball), morphological 
overgeneralisations (e.g. The ball hitted) and additional modifying phrases (e.g. He kicked the ball in the goal).

The mean number of sentences of each type produced by each child is shown in Figure 12, out of a possible maximum of 10. As can be seen in Figure 12, children produced large proportion of sentences containing errors, in both directions. Production priming therefore seems to be a powerful tool for eliciting overgeneralisation errors. However, given that the rate of these errors recorded in natural speech is so low, perhaps our implementation of the methodology has produced an unrealistically high number of errors. Nevertheless, as will be shown below, the rate of errors did vary considerably between verbs, and we are therefore still able to test our hypotheses using these data (albeit bearing in mind this caveat).

\section{INSERT HERE}

Figure 12: Number of overgeneralization errors (light red bars) in each condition. Dark red bars show other types of erroneous responses. Light and dark green bars show different types of correct response. Grey bars show other uses of the target verb. Total number of trials per condition is 640 (64 children $x 10$ responses). Neither bar reaches this maximum due to the exclusion of trials where the child did not produce the target verb.

The binary dependent variable for this experiment was the child's response: overgeneralisation error (1, corresponding to the light red bars in Figure 12) or other use of the target verb (0, corresponding to all other bars in Figure 12), with all responses in which the child did not use the target verb excluded from the analysis. As the dependent variable was binary, results were analysed using the glmer function of the lme4 package (version 1.114, Bates et al., 2014), with family=binomial. Predictor variables were the same as in Experiment 1.

\section{INSERT HERE \\ Figure 13. Relationship between preemption / entrenchment / verb semantics and transitivisation errors for intransitive-only verbs \\ Figure 14. Relationship between preemption / entrenchment / verb semantics and intransitivisation errors for transitive-only verbs}

Figures 13-14 plot the rate of transitivisation errors (for intransitive-only verb) and intransitivisation errors (for transitive-only verbs). All predictors appear to pattern in the expected direction: for semantics, transitivisation errors increase, and intransitivisation errors decrease, as verbs increase on the semantic event-merge measure. This is expected, since a high score on the event-merge measure is associated with transitive, rather than intransitive 
semantics (e.g. The girl killed the fly, for which, prototypically, the killing and being-killed merge into a single event in time and space). For preemption and entrenchment, rates of transitivisation errors (e.g. *The man laughed the girl) are lowest when the relevant verb is of high frequency in periphrastic (preemption) and other (entrenchment) constructions relative to the transitive construction, as indicated by negative values. Rates of intransitivisation errors (e.g. * The city destroyed) are lowest when the relevant verb is of high frequency in passive (preemption) and other (entrenchment) constructions relative to the intransitive construction, again as indicated by negative values.

However, with a single exception, these apparent effects were not confirmed by the statistical models (see Table 17). For the single-predictor models, all with maximal random effects structure (except that correlations were disallowed for the transitive-only verbs dataset), only preemption was significant, and only for transitivisation errors of intransitive only verbs (e.g. *The man laughed the girl). Preemption was no longer significant in the multiple-predictor models, both with random intercepts only, though this is unsurprising given its collinearity with the entrenchment predictor.

Table 17. Production study.

\section{Single-predictor models}

AIC Chi p (Chi)

Transitivisation errors for intransitive-only verbs

Preemption

Entrenchment

$403.1 \quad 5.6 \quad 0.0176 *$

Semantics

$403.1 \quad 3.4$

0.0650 .

0.6705

Intransitivisation errors for transitive-only verbs

Preemption

Entrenchment

$454.2 \quad 0.0$

$454.4 \quad 0.7$

0.9713

0.4051

$460.9 \quad 1.6$

0.2078

\section{Simultaneous models \\ AIC Chi p (Chi)}

$\begin{array}{lll}401.6 & 2.6 & 0.1053 \\ 399.4 & 0.5 & 0.4972 \\ 398.9 & 0.0 & 0.9414\end{array}$

$\begin{array}{lll}455.4 & 0.0 & 0.9788 \\ 458.1 & 2.7 & 0.1000 \\ 457.2 & 1.8 & 0.1802\end{array}$

\section{Discussion (Study 2: Production)}

The production priming method used here was successful in eliciting large numbers of overgeneralisation errors with both transitive-only and intransitive-only verbs. This allowed us to test the predictions of the entrenchment, semantics and preemption hypotheses on 
production data, something which has not been possible with spontaneous production data given the sparsity of these errors in naturalistic speech. However, the artificially high error rate has potentially caused a number of unintended consequences.

Firstly, the pattern of findings observed for production, with only preemption a significant predictor of error rates, and only for the production of transitive sentences, contrasts with the pattern observed for judgments where all three predictors were significant (at least in single-predictor models). One possibility is that there is no relationship between production and comprehension of overgeneralisation errors; that the factors important in the production of these errors are not related to the factors involved in their comprehension. However, this seems a radical and highly unlikely conclusion to draw. More likely, then, is the possibility that the method itself has elicited a pattern of responses that obscures the effects of entrenchment, semantics and preemption in children's avoidance of overgeneralisation errors in production. For example, the binary outcome measure used in the production task ( $1=$ overgeneralisation error, $0=$ other use of the verb) is a far less sensitive measure than the continuous measure used in the judgment task (5-point scale). Increasing the number of participants in the production study, then, might have allowed the effects of the semantic and statistical measures to have been better observed.

In terms of semantics, a potential problem with the production study is that discrete verb classes were used to divide the verbs into several sets, with pre-determined transitiveonly or intransitive-only verbs in each; transitive-only verbs were primed with only intransitive-only verbs and vice versa. This was done in order to provide the optimum conditions in which to prime error production. However, it also means that we are unable to combine rates of production of each sentence type for verbs of each type (since the transitiveonly and intransitive-only verbs were not tested in the same conditions). If verb semantics are used to distinguish between verbs which can and cannot be used in each construction, then our method has, in fact, prevented the semantics mechanism from being demonstrated in production. It seems quite likely that verb semantics could, in principle, explain the different behaviour of different verbs in production if the study were set up so that we could directly compare verbs of different types (i.e. without removing some of the most salient semantic distinctions between the verbs in advance).

A final, more general problem that affects the present study is the large variation in error rates between children, as illustrated in Figures 15-16, which show the mean rates of transitivisation and intransitivisation errors for each verb with $95 \%$ confidence intervals. For most verbs, the confidence interval spans around 0.5 points on the $0-1$ scale. For example, if a 
verb has a mean error rate of 0.5 , the confidence interval ranges from around 0.25 to around 0.75. Consequently, the confidence intervals for the verbs with the highest and lowest error rates overlap, making by-verb estimates of error rate somewhat unreliable. This, again, makes it very difficult to observe any effects of entrenchment, semantics and preemption.

\section{INSERT \\ Figure 15. Mean by-verb rates of transitivisation error and $95 \%$ confidence intervals Figure 16. Mean by-verb rates of intransitivisation error and $95 \%$ confidence intervals}

\section{General discussion}

In this study we adopted a multi-method approach to the question of how children avoid argument structure overgeneralisation errors. In Experiment 1, we investigated how statistical and semantic constraints influence the way in which children (aged 5-6 and 9-10 years) and adults judge the grammatical acceptability of 120 verbs in transitive and intransitive sentences. In Experiment 2, we successfully used a priming methodology to elicit overgeneralisation errors from five- to 6-year-old children, to investigate whether the same constraints appear to be operational in production. For judgments, a clear picture emerged: for all ages, for judgments of transitives, intransitives and difference scores, the data show effects of semantics and statistics: preemption and/or entrenchment (we cannot say which, due to collinearity), mirroring the pattern observed in a recent meta-analysis of similar studies of other constructions. For production, the picture was less clear, with an effect of preemption observed for transitivisation errors with intransitive-only verbs (e.g. *The man laughed the girl), but no other effects, across both these errors and intransitivisation errors with transitiveonly verbs (e.g. *The city destroyed). We concluded that, although it is possible to elicit overgeneralisation errors from five- to 6-year-old children, the most likely explanation is that effects of verb semantics and preemption/entrenchment are real, but obscured by particular features of our production task; in particular, (a) the binary nature of the dependent measure, (b) the splitting of verbs into two semantic types, and (c) a high degree of variability between children. We hope that future production studies will refine this method and overcome at least some of these shortcomings.

In the meantime, if we proceed on the basis of the present judgment findings, and the meta-analytic synthesis to which they contribute, the current best evidence suggests that 
effects of preemption, entrenchment and semantics are real, and, furthermore, observed across most of the major argument structure constructions for which children make errors, at least in English. This raises the question of what kind of account can explain all three effects.

When considering this question in the light of the previous version of the judgmentdata meta-analytic synthesis, Ambridge et al. (2018) discussed three accounts. First, Ambridge and colleagues' FIT account (Ambridge \& Lieven, 2011; Ambridge et al., 2012) posits that verb-in-construction frequency (explaining both entrenchment and preemption effects) combines with construction relevance and the semantic 'fit' of the verb in the construction when selecting the best construction to convey the message. Constructions that are heard more frequently with a verb and have a better fit with that verb will be activated more strongly and will therefore be more likely to be chosen. Ambridge and Blything's (2016) connectionist instantiation of the FIT account was able to simulate both the overall overgeneralisation-then-retreat pattern, and the by-verb pattern of participants' judgments, observed for the DO-dative construction (e.g. Bart gave Lisa a present)

Second, Goldberg's (in press) CENSE-ME account is similar in many ways to the FIT account, but places more emphasis on competition between constructions (preemption, rather than entrenchment) and on error-driven learning. This account has also been instantiated as a computational model, which uses a Bayesian clustering algorithm to group together verbs with similar semantic and distributional properties (Barak, Goldberg \& Stevenson, 2016). Importantly, this model outperformed Ambridge and Blything's (2016) model of the dative, in that it could explain not only the pattern of judgments observed for the DO-dative, but also the PO-dative (e.g. Bart gave a present to Lisa), and difference scores.

Third, Ambridge et al. (2018) concluded that the most promising approach lies with a third type of account: discriminative learning (e.g. Ramscar, Dye \& McCauley, 2013), which has its origins in the animal learning literature (e.g. Rescorla \& Wagner, 1972). The advantages of this approach are that (1) it yields effects of preemption, entrenchment and semantics from a single learning mechanism, (2) it is straightforwardly formalised using a simple learning algorithm and (3) it already enjoys support in many domains of language acquisition, including word learning (e.g. Ramscar, Dye \& Klein, 2013) and morphosyntax (e.g. Arnon \& Ramscar, 2012). Ambridge et al. (2018: 51), summarise the general approach as follows: 
"The key feature of discriminative-learning models is that learning is a process by which prediction error is used to discriminate uninformative versus informative cues. Thus, such models weight cue strength from both cue-outcome pairings that are observed, and cue-outcome pairings that are predicted, but not observed. For example, suppose that a rat learns to associate a tone (cue) with a shock (outcome), and so freezes in anticipation of a shock whenever the tone is heard. In an otherwise-identical setup with additional tones that are not followed by a shock, learning is attenuated. Indeed, the likelihood of the rat freezing in response to the tone decreases in proportion to the background rate of tones that are not followed by a shock (Rescorla, 1968). Discriminative learning models are also designed to explain behavior in situations with multiple cues. For example, if a rat has already learned to associate a tone (cue) with a shock (outcome), its ability to learn that another cue (say a buzzer) also predicts this shock is reduced; a phenomenon known as blocking (Kamin, 1969; though see Maes, Boddez, Alfei, Krypotos, D’Hooge, De Houwer \& Beckers, 2016, for 15 failures to replicate). Cues can combine as well as compete. For example, a rat can learn that a buzzer predicts a shock, but only if a tone is also present; or alternatively - only if a tone is absent (phenomena known respectively as positiveand negative occasion-setting; Holland, 1983). More generally, Bellingham, GilletteBellingham and Kehoe (1985) demonstrated that multiple cues can combine in a nonlinear fashion."

In principle, then, this account could be applied to the domain of (in)transitivisation errors as follows. The learning situation can be formalised such that children learn the predictive value of real-world semantic cues for particular linguistic outcomes (e.g. CAUSE + BREAK $\rightarrow$ "X broke Y"; CAUSE + ROLL $\rightarrow$ "X rolled Y"). Having learned this relationship, children produce errors such as *The man laughed the girl, because the cue of CAUSE is highly predictive of the transitive "X VERBed Y" structure. Errors cease as children learn a more fine-grained discrimination: in fact, it is the COMBINATION of the semantic cues CAUSE AND, CRUCIALLY, SINGLE-EVENT (as per the present event-merge measure) that is most predictive of the transitive "X VERBed Y" structure (e.g. CAUSE + BREAK + SINGLE-EVENT $\rightarrow$ "X broke Y"; CAUSE + ROLL + SINGLE-EVENT $\rightarrow$ "X rolled Y"). The rival combination of semantic cues CAUSE + SEPARATE-EVENTS is instead highly predictive of the periphrastic causative construction with make (e.g. CAUSE + 
BREAK + SEPARATE-EVENTS $\rightarrow$ "X made Y" break; CAUSE + ROLL + SEPARATE-

EVENTS $\rightarrow$ "X made Y roll”). As children learn this discrimination, they will learn to say not *The man laughed the girl, but The man made the girl laugh i.e. (CAUSE + LAUGH + SEPARATE-EVENTS $\rightarrow$ "X made Y laugh").

This formalisation corresponds closely to the notion of preemption, but it does so in a way that yields effects of verb semantics and entrenchment for free. Any verb whose semantics are such that it is more likely to appear in a SEPARATE-EVENTS than SINGLEEVENT scenario (e.g. dance, sing, run) will automatically be generalised into the periphrastic causative, rather than the transitive, as the fine-grained discrimination set out above is learned. Entrenchment effects arise as a function of the fact that (for example) LAUGH + CAUSE events will often occur in the absence of the transitive X VERBed Y construction (e.g. if the speaker chooses simply to say The girl laughed) since learning takes place whenever a predicted outcome (LAUGH + CAUSE $\rightarrow$ "X VERBed Y") FAILS to occur. On this view, entrenchment effects are observed because the overall frequency of laugh in non-causative utterances (e.g. The girl laughed) is a proxy for the frequency of laughing events; in principle, it is the latter that is relevant.

In conclusion, whether or not any of three types of account that we have set out here is along the right lines, the present study has contributed to a growing body of evidence which suggests that any successful account of the retreat from argument structure overgeneralisation errors will need to explain effects of preemption, entrenchment and verb semantics that are now well established, at least in judgment studies. Future studies should aim to refine the production priming method that we have used here, in order to better investigate the relationship between judgments and production with regard to this debate, which lies at the very heart of theorising about child language acquisition. 


\section{References}

Ambridge, B. (2013). How do children restrict their linguistic generalizations?: An (un)grammaticality judgment study. Cognitive Science, 37(3), 508-543.

Ambridge, B., Barak, L., Wonnacott, E., Bannard, C., \& Sala, G. (2018). Effects of both preemption and entrenchment in the retreat from verb overgeneralization errors: Four reanalyses, an extended replication, and a meta-analytic synthesis. Collabra: Psychology, 4(1), 23.

Ambridge, B., Bidgood, A., Twomey, K. E., Pine, J. M., Rowland, C. F., \& Freudenthal, D. (2015). Preemption versus entrenchment: Towards a construction-general solution to the problem of the retreat from verb argument structure overgeneralisation. PLoS ONE, 10(4): e0123723.

Ambridge, B., \& Blything, R. P. (2016). A connectionist model of the retreat from verb argument structure overgeneralization. Journal of Child Language, 43(6), 1245-1276.

Ambridge, B., \& Lieven, E. V. M. (2011). Child Language Acquisition: Contrasting theoretical approaches. Cambridge, UK: Cambridge University Press.

Ambridge, B., Pine, J. M. \& Rowland, C. F. (2012). Semantics versus statistics in the retreat from locative overgeneralization errors. Cognition, 123, 260-279.

Ambridge, B., Pine, J. M., Rowland, C. F. \& Chang, F. (2012). The roles of verb semantics, entrenchment, and morphophonology in the retreat from dative argument-structure overgeneralization errors. Language, 88(1), 45-81.

Ambridge, B., Pine, J. M, Rowland, C. F., Freudenthal, D., \& Chang, F. (2014). Avoiding dative overgeneralization errors: Semantics, statistics or both? Language, Cognition and Neuroscience, 29(2), 218-243.

Ambridge, B., Pine, J. M., Rowland, C. F., Jones, R. L. \& Clark, V. (2009). A semanticsbased approach to the "no negative evidence" problem. Cognitive Science, 33(7), 1301-1316.

Ambridge, B., Pine, J. M., Rowland, C. F., \& Young, C. R. (2008). The effect of verb semantic class and verb frequency (entrenchment) on children's and adults' graded judgements of argument-structure overgeneralization errors. Cognition. 106(1), 87129.

Arnon, I., \& Ramscar, M. (2012). Granularity and the acquisition of grammatical gender: How order-of-acquisition affects what gets learned. Cognition, 122(3), 292-305. 
Barak, L., Goldberg, A. E., \& Stevenson, S. (2016). Comparing computational cognitive models of generalization in a language acquisition task. In Proceedings of the 2016 Conference on Empirical Methods in Natural Language Processing (pp. 96-106).

Barr, D. J., Levy, R., Scheepers, C., \& Tily, H. J. (2013). Random effects structure for confirmatory hypothesis testing: Keep it maximal. Journal of memory and language, 68(3), 255-278.

Bates, D., Maechler, M., Bolker, B., \& Walker, S. (2017). lme4: Linear mixed-effects models using Eigen and s4. R package version 1.1-14. http://cran.r-project.org/package=lme4.

Bellingham, W. P., Gillette-Bellingham, K., \& Kehoe, E. J. (1985). Summation and configuration in patterning schedules with the rat and rabbit. Animal Learning \& Behavior, 13(2), 152-164.

Bidgood, A., Ambridge, B., Pine, J. M., \& Rowland, C. F. (2014). The retreat from locative overgeneralisation errors: A novel verb grammaticality judgment study. PLoS ONE, 9(5), e97634.

Blything, R., Ambridge, B., \& Lieven, E. V. M. (2014). Children use statistics and semantics in the retreat from overgeneralization. PLoS ONE, 9(10) e110009.

Bowerman, M. (1981). The child's expression of meaning: Expanding relationships among lexicon, syntax and morphology. Paper presented at the New York Academy of Sciences Conference on Native Language and Foreign Language Acquisition.

Braine, M. D. S., \& Brooks, P. J. (1995). Verb argument structure and the problem of avoiding an overgeneral grammar. In M. Tomasello \& W. E. Merriman (Eds.), Beyond names for things: young children's acquisition of verbs (pp. 352-376). Hillsdale, NJ: Erlbaum.

Branigan, H. P., \& Pickering, M. J. (2017). An experimental approach to linguistic representation. Behavioral and Brain Sciences, 40.

British National Corpus (2007). BNC XML edition ( $3^{\text {rd }}$ edition.). Oxford: Oxford University Computing Services (distributor), on behalf of the BNC Consortium.

Brooks, P. J., \& Tomasello, M. (1999). How children constrain their argument structure constructions. Language, 75(4), 720-738.

Brooks, P. J., \& Zizak, O. (2002). Does preemption help children learn verb transitivity? Journal of Child Language, 29, 759-781.

Goldberg, A. E. (1995). Constructions: A construction grammar approach to argument structure. Chicago: University of Chicago Press. 
Goldberg, A. E. (in press). Explain Me This: Creativity, Competition, and the Partial Productivity of Constructions. Princeton, NJ: Princeton University Press https://press.princeton.edu/titles/13271.html

Gropen, J., Pinker, S., Hollander, M., \& Goldberg, R. (1991). Affectedness and Direct Objects - the Role of Lexical Semantics in the Acquisition of Verb Argument Structure. Cognition, 41(1-3), 153-195.

Holland, P. C. (1983). Occasion setting in Pavlovian feature positive discriminations. In: Commons, M. L., Herrnstein, R. J., \& Wagner, A. R. (Eds.), Quantitative analyses of behavior: Discrimination processes, 4, 183-206. New York: Ballinger.

Hopper, P. J., \& Thompson, S. A. (1980). Transitivity in grammar and discourse. Language, 56(2), 251-299.

Kamin, L. J. (1969). Predictability, surprise, attention, and conditioning. In: Cambell, B. A., \& Church, R. M. (Eds.), Punishment and Aversive Behavior. New York: AppletonCentury-Crofts.

Knapp, G., \& Hartung, J. (2003). Improved tests for a random effects meta-regression with a single covariate. Statistics in Medicine, 22, 2693-2710.

Konstantopoulos, S. (2011). Fixed effects and variance components estimation in three-level metaanalysis. Research Synthesis Methods, 2, 61-76.

Levin, B. (1993). English verb classes and alternations: A preliminary investigation. Chicago: University of Chicago Press.

Lord, C. (1979). Don't you fall me down: Children's generalizations regarding cause and transitivity. In Papers and reports on child language development (PRCLD) 17. Stanford, CA: Stanford University Department of Linguistics.

Maes, E., Boddez, Y., Alfei, J. M., Krypotos, A. M., D’Hooge, R., De Houwer, J., \& Beckers, T. (2016). The elusive nature of the blocking effect: 15 failures to replicate. Journal of Experimental Psychology: General, 145(9), e49.

Næss, A.. (2007). Prototypical transitivity (Vol. 72). Philadelphia: John Benjamins Publishing.

Peirce, J. W. (2009). Generating stimuli for neuroscience using PsychoPy. Frontiers in Neuroinformatics, 2, 10.

Pinker, S. (1989). Learnability and cognition: The acquisition of argument structure. Cambridge, MA: MIT.

Ramscar, M., Dye, M., \& McCauley, S. M. (2013). Error and expectation in language learning: The curious absence of mouses in adult speech. Language, 89(4), 760-793. 
Ramscar, M., Dye, M., \& Klein, J. (2013). Children value informativity over logic in word learning. Psychological Science, 24(6), 1017-1023.

R Core Team (2018). R: A language and environment for statistical computing. Vienna: R Foundation for Statistical Computing. http://www.r-project.org/.

Rescorla, R. A. (1968). Probability of shock in the presence and absence of CS in fear conditioning. Journal of Comparative and Physiological Psychology, 66(1), 1.

Rescorla, R. A., \& Wagner, A. R. (1972). A theory of Pavlovian conditioning: Variations in the effectiveness of reinforcement and nonreinforcement. Classical conditioning II: Current research and theory, 2, 64-99.

Rowland, C. F., Chang, F., Ambridge, B., Pine, J. M., \& Lieven, E. V. M. (2012). The development of abstract syntax: Evidence from structural priming and the lexical boost. Cognition, 125(1), 49-63.

Schmidt, F. L., \& Hunter, J. E. (2015). Methods of meta-analysis: Correcting error and bias in research findings (3rd ed.). Newbury Park, CA: Sage.

Shibatani, M., \& Pardeshi, P. (2002). The causative continuum. Typological studies in language, 48, 85-126.

Stefanowitsch, A. (2008). Negative evidence and preemption: A constructional approach to ungrammaticality. Cognitive Linguistics, 19(3), 513-531.

Theakston, A. L. (2004). The role of entrenchment in children's and adults' performance on grammaticality judgement tasks. Cognitive Development, 19(1), 15-34.

Viechtbauer, W. (2010). Conducting meta-analysis in R with the metafor package. Journal of Statistical Software, 36, 1-48. Retrieved from http://brieger.esalq.usp.br/CRAN/web/packages/metafor/vignettes/metafor.pdf

Wurm, L. H., \& Fisicaro, S. A. (2014). What residualizing predictors in regression analyses does (and what it does not do). Journal of Memory and Language, 72(1), 37-48. 


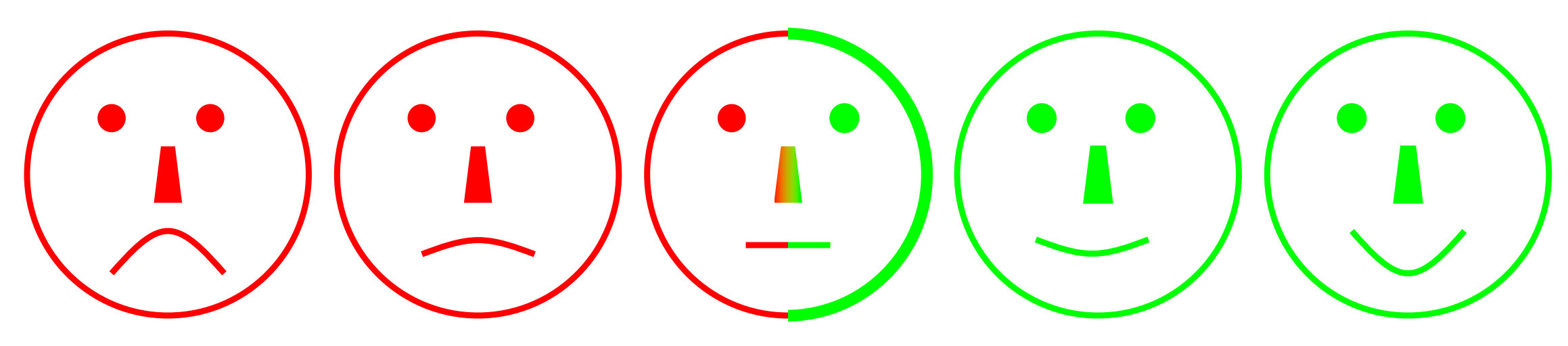




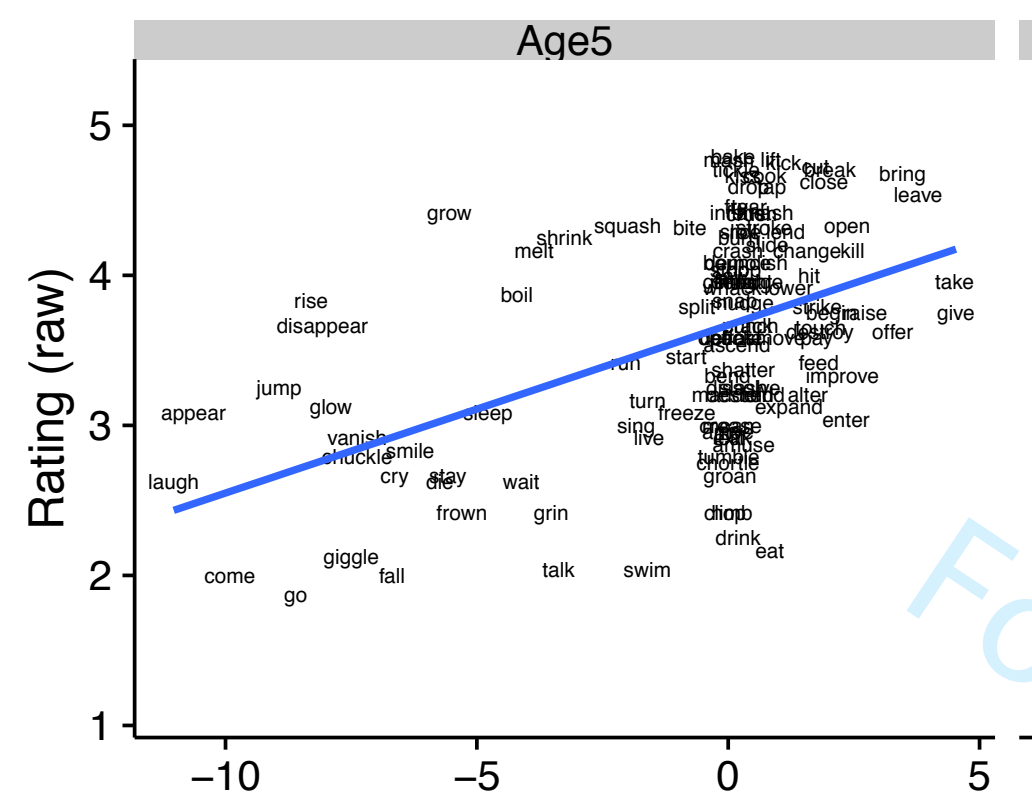

\section{Transitive judgments $\sim$ Preemption}
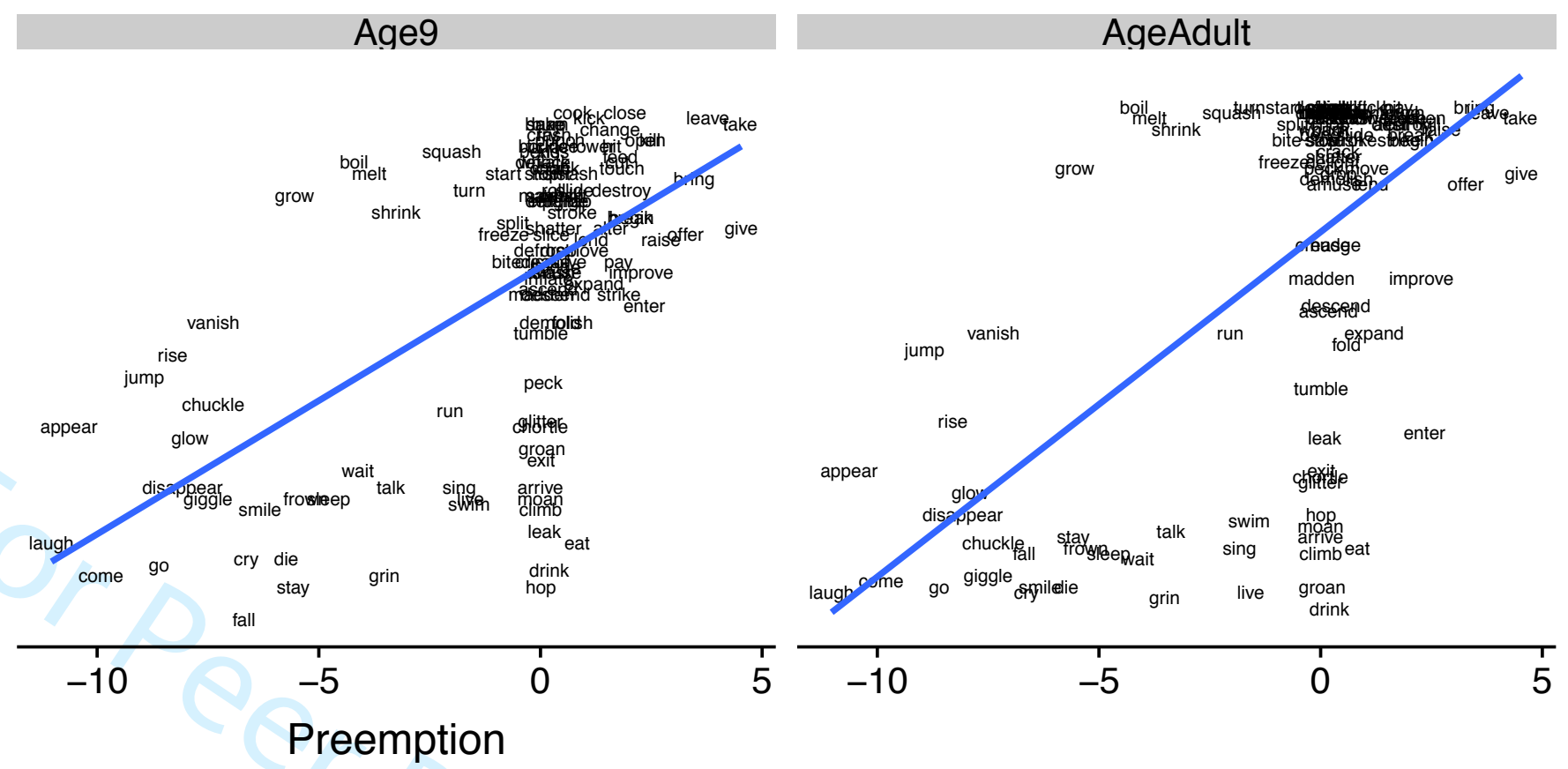

Intransitive judgments $\sim$ Preemption
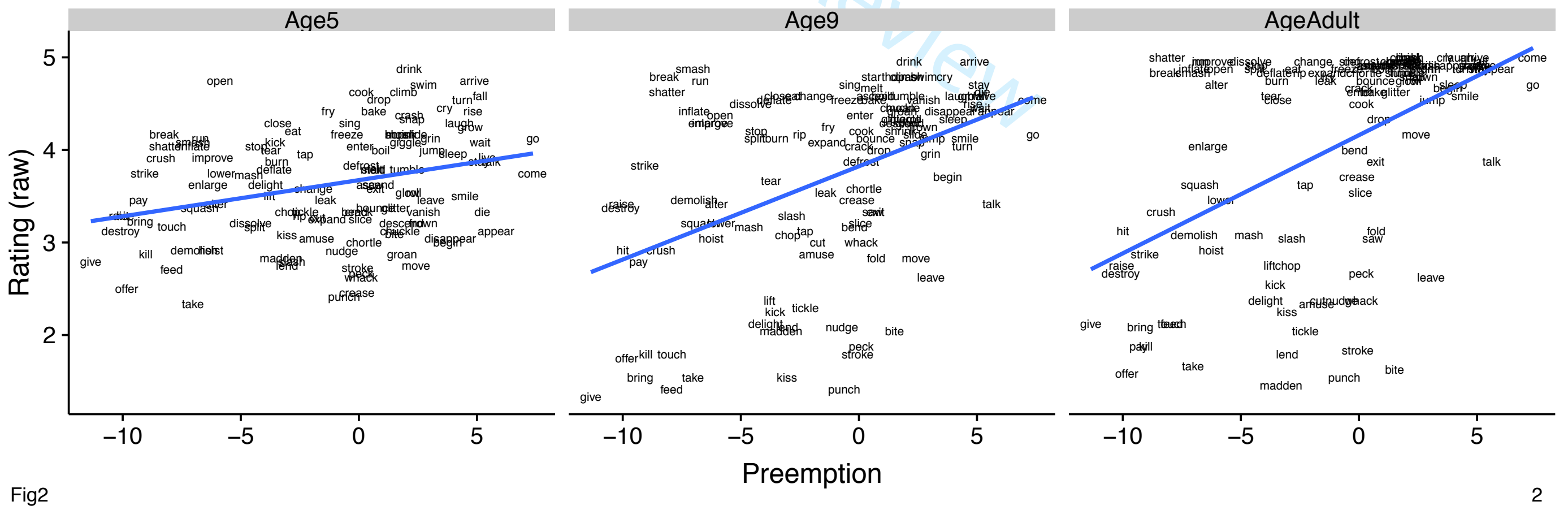


\section{Draft For Review}

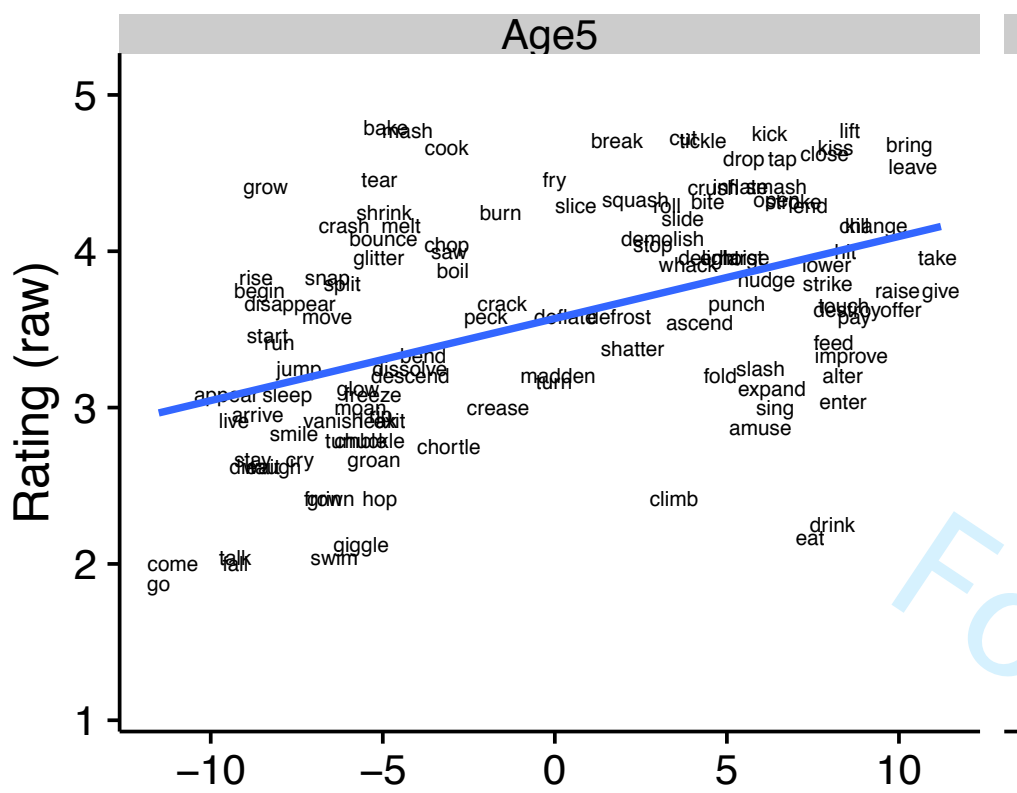

\section{Transitive judgments $\sim$ Entrenchment}
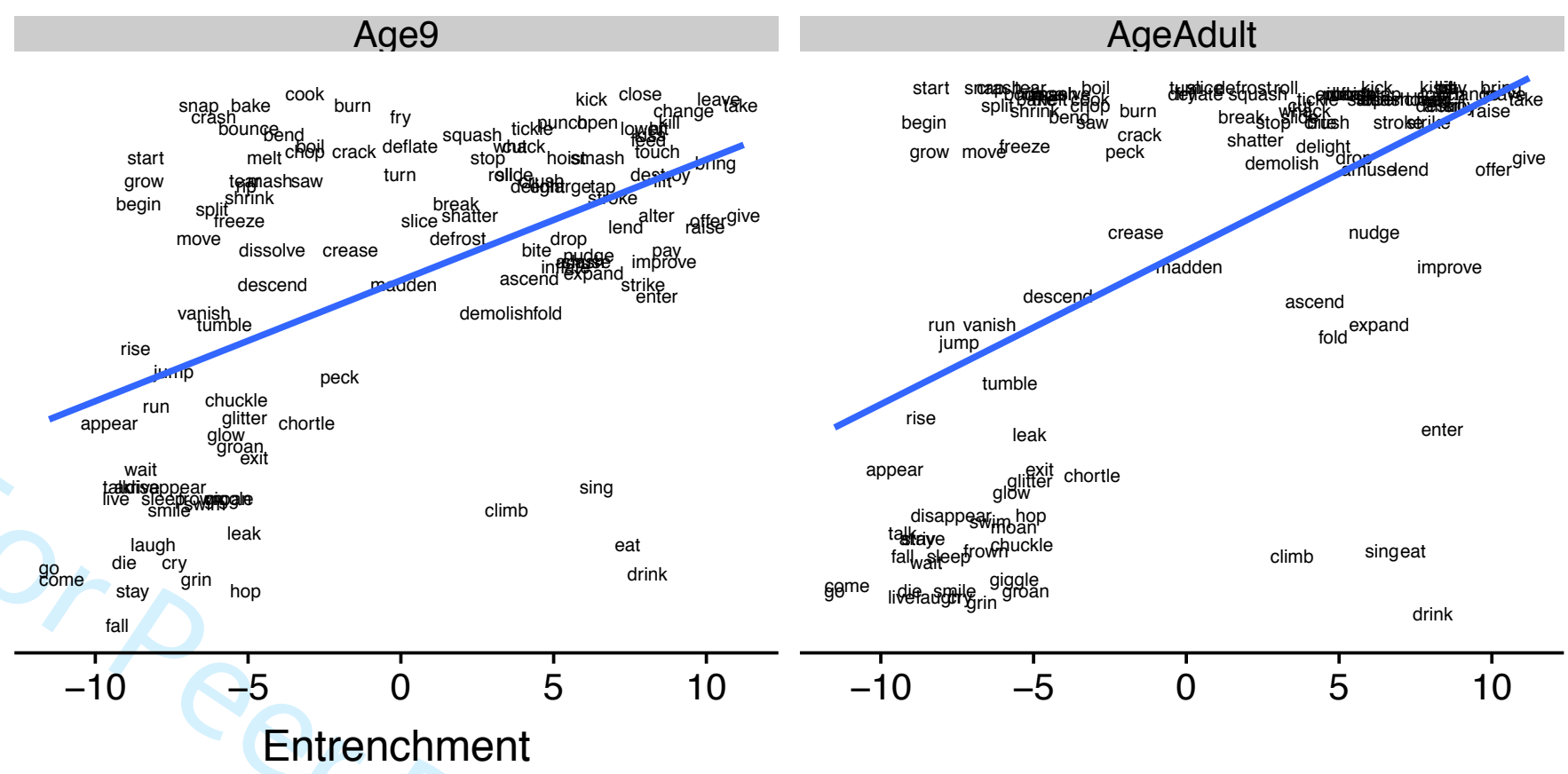

\section{Intransitive judgments Entrenchment}
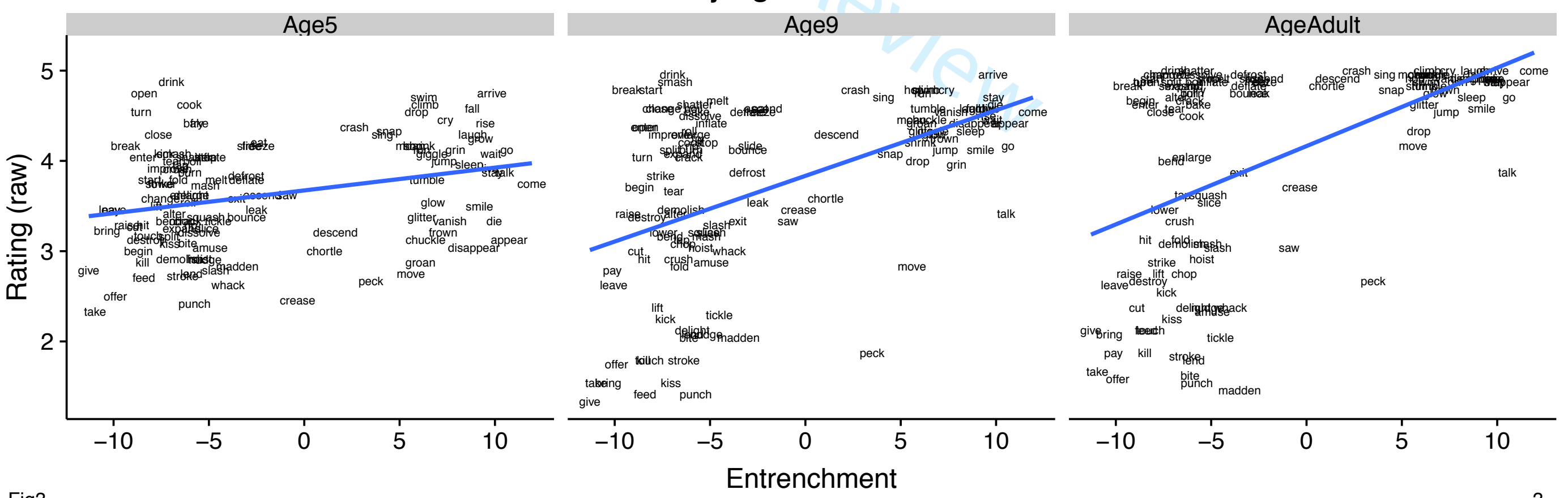


\section{Transitive judgments $\sim$ Verb semantics}
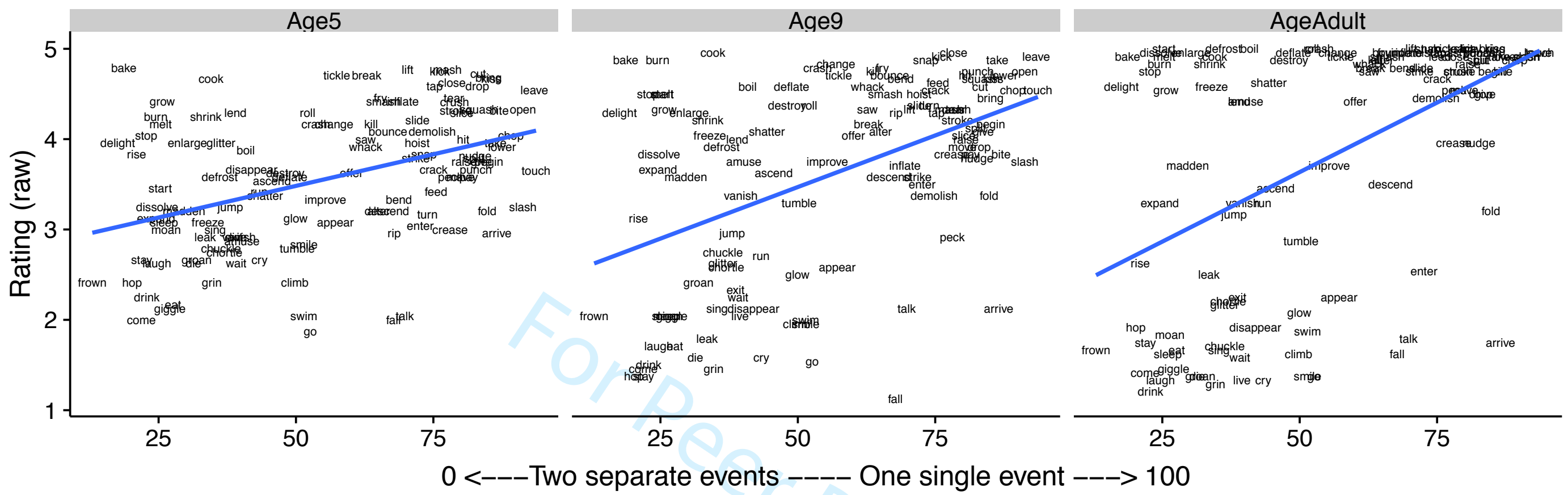

\section{Intransitive judgments $\sim$ Verb semantics}
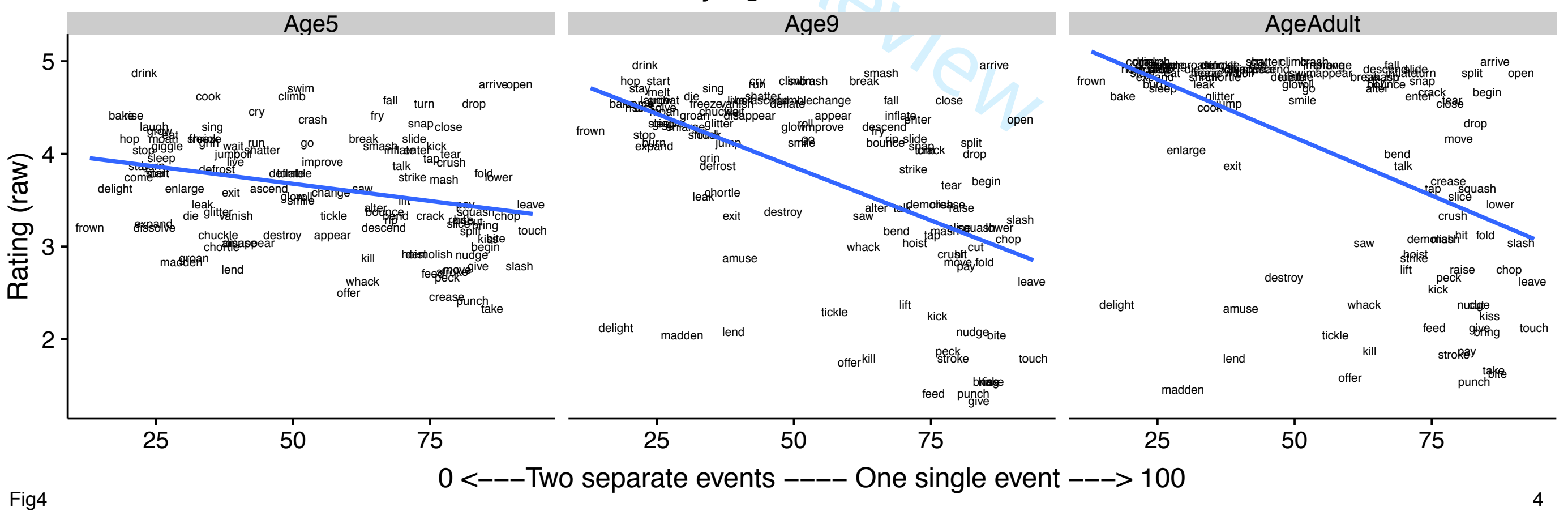


\section{Difference score judgments Preemption}

Age5

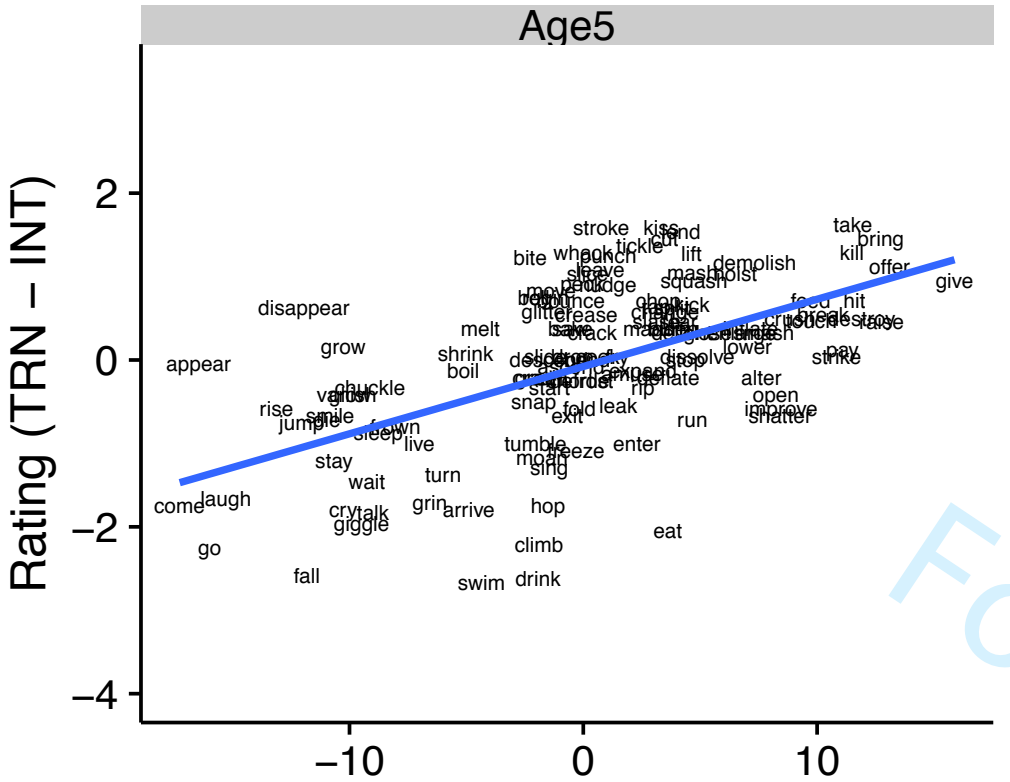

Age9

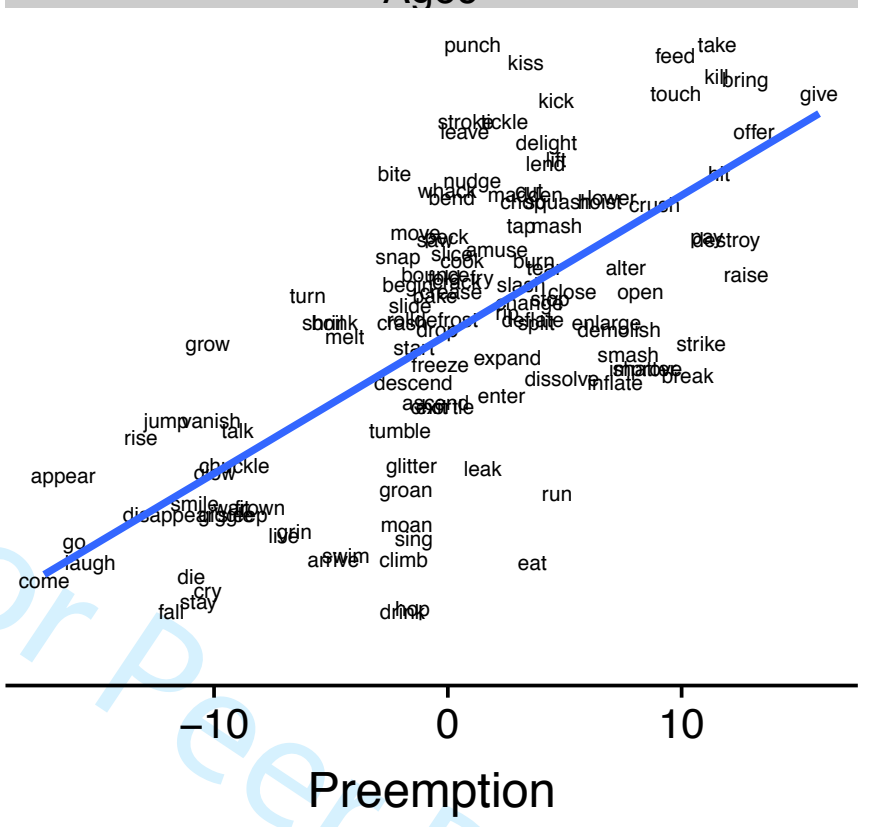

AgeAdult

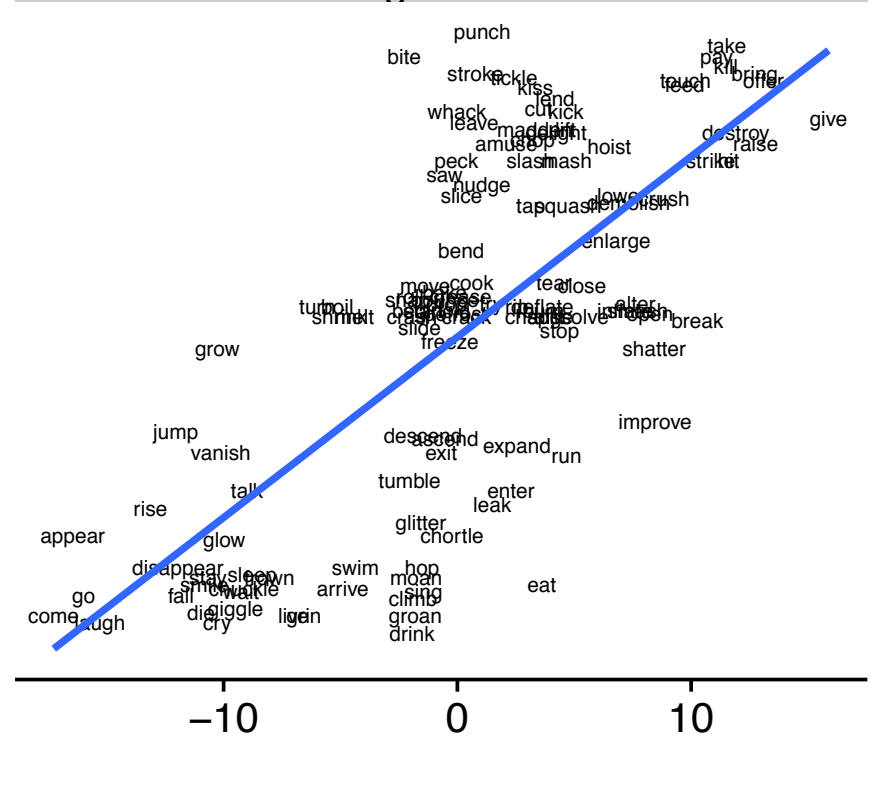

\section{Difference score judgments Entrenchment}

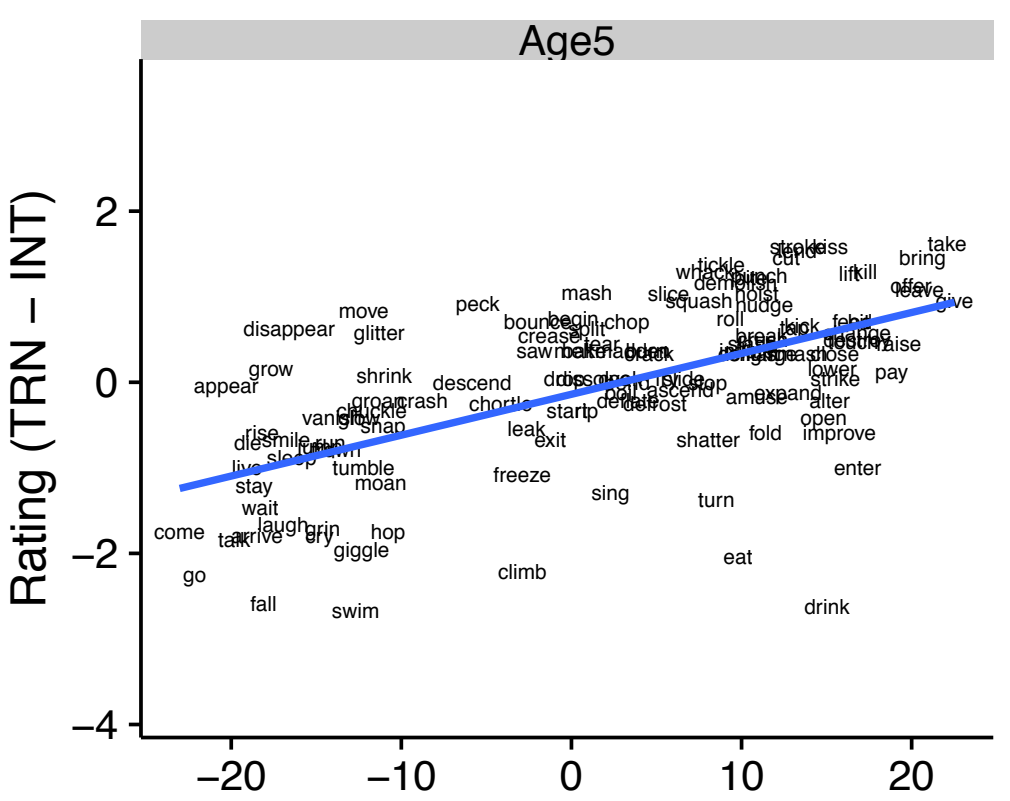

Fig5-7

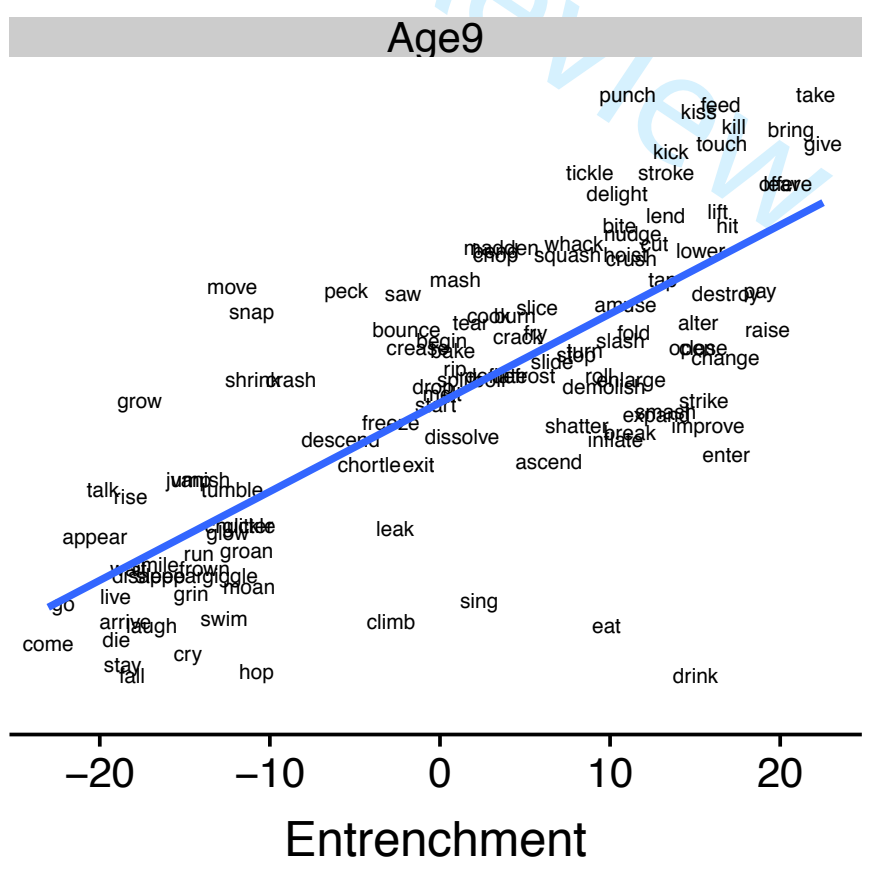




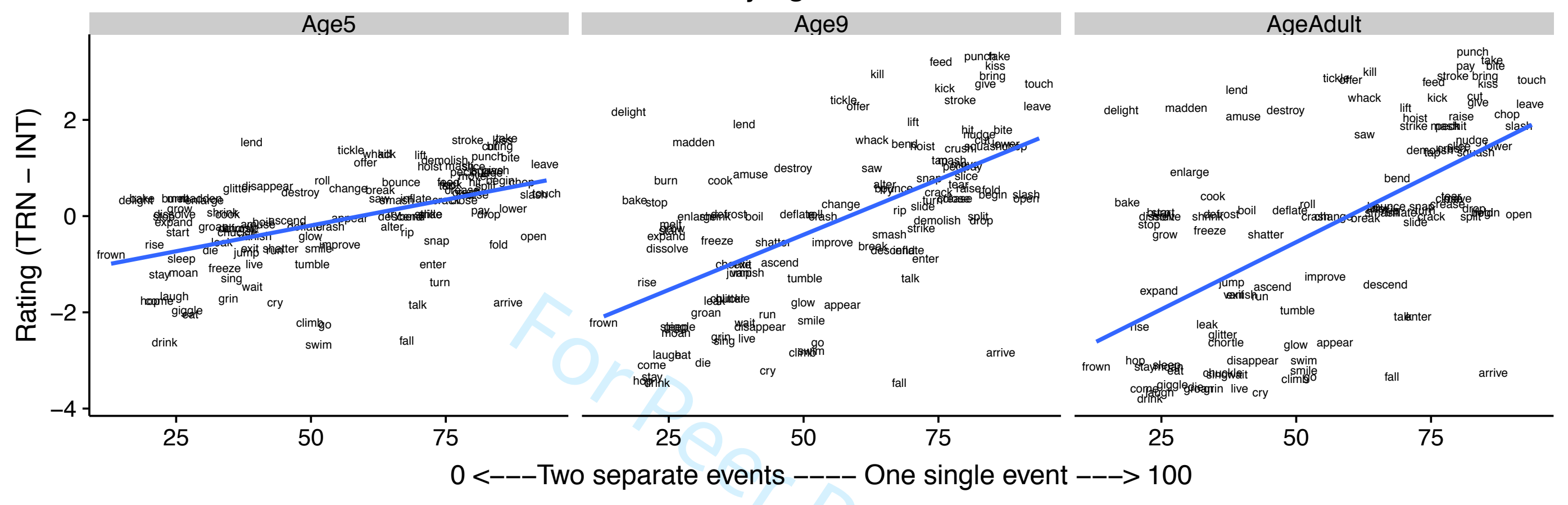




\author{
Figure_Locative_Age_18Adult \\ Figure_Locative_Age5_6 \\ Figure_Locative_Age9_10 \\ Ground_Locative_Age_18Adult \\ Ground_Locative_Age5_6 \\ Ground_Locative_Age9_10 \\ DO_Dative_Age_18Adult \\ DO_Dative_Age5_6 \\ DO_Dative_Age9_10 \\ PO_Dative_Age_18Adult \\ PO_Dative_Age 5_6 \\ PO_Dative_Age9_10 \\ Various_Age_18Adult \\ Various_Age5_6 \\ Various_Age9_10 \\ Un_Verb_Age_18Adult \\ Un_Verb_Age5_6 \\ Un_Verb_Age9_10 \\ Un_Verb_Age_18Adult \\ Transitive_Age_18Adult \\ Transitive_Age5_6 \\ Transitive_Age9_10 \\ Intransitive_Age_18Adult \\ Intransitive_Age5_6 \\ Intransitive_Age9_10
}

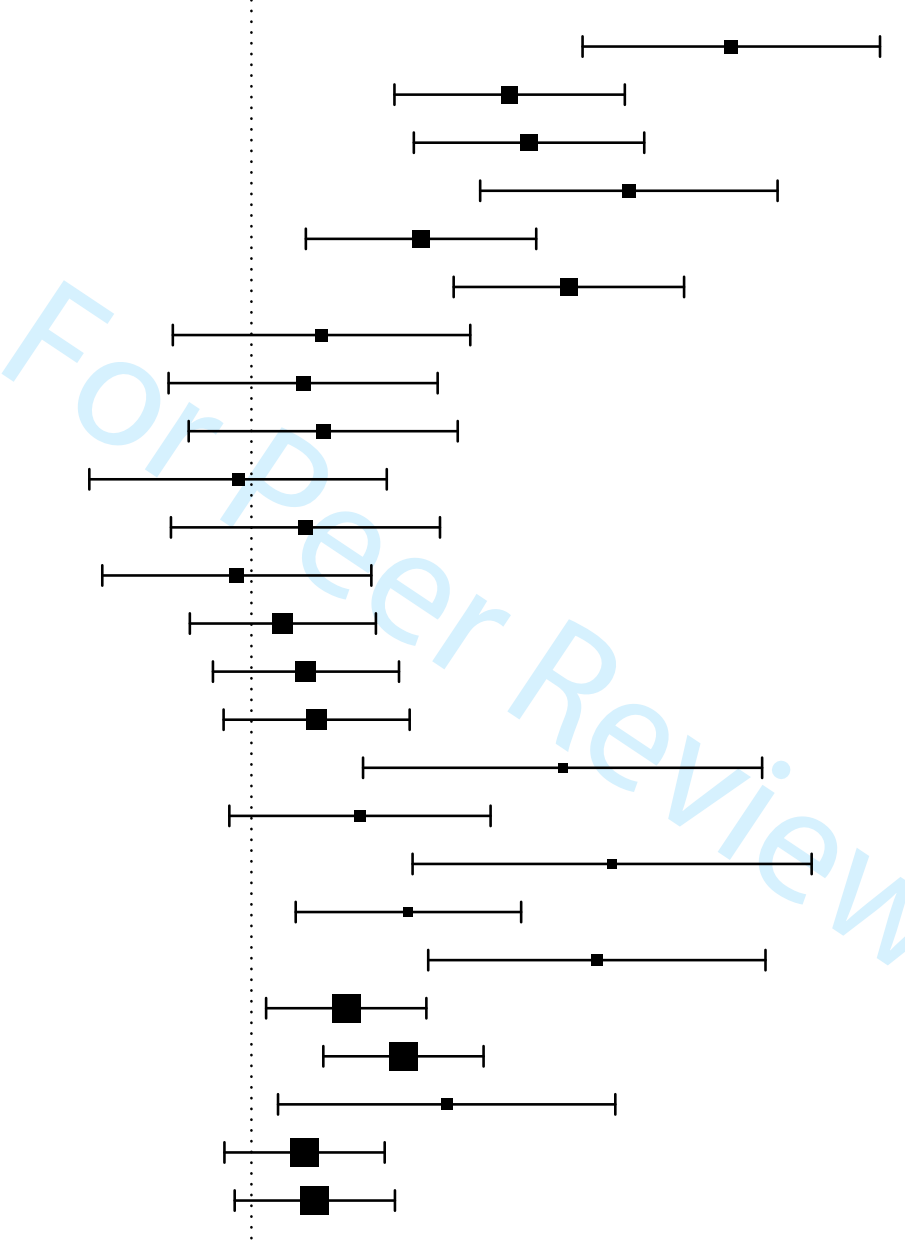

$1.22[0.84,1.59]$

$0.65[0.36,0.95]$

$0.70[0.41,1.00]$

$0.96[0.58,1.33]$

$0.43[0.14,0.72]$

$0.81[0.51,1.10]$

$0.18[-0.20,0.56]$

$0.13[-0.21,0.47]$

$0.18[-0.16,0.52]$

$-0.03[-0.41,0.34]$

$0.14[-0.20,0.48]$

$-0.04[-0.38,0.30]$

$0.08[-0.16,0.32]$

$0.14[-0.10,0.37]$

$0.17[-0.07,0.40]$

$0.79[0.28,1.30]$

$0.28[-0.06,0.61]$

$0.91[0.41,1.42]$

$0.40[0.11,0.68]$

$0.88[0.45,1.30]$

0.24 [0.04, 0.44]

0.39 [ $0.18,0.59]$

$0.50[0.07,0.92]$

$0.13[-0.07,0.34]$

RE Model

0.36 [ NA, NA]

\begin{tabular}{|c|c|c|c|c|}
\hline T. & $i$ & $T$ & $T$ & $T$ \\
\hline-0.5 & 0 & 0.5 & 1 & 1.5 \\
\hline
\end{tabular}

Observed Outcome 

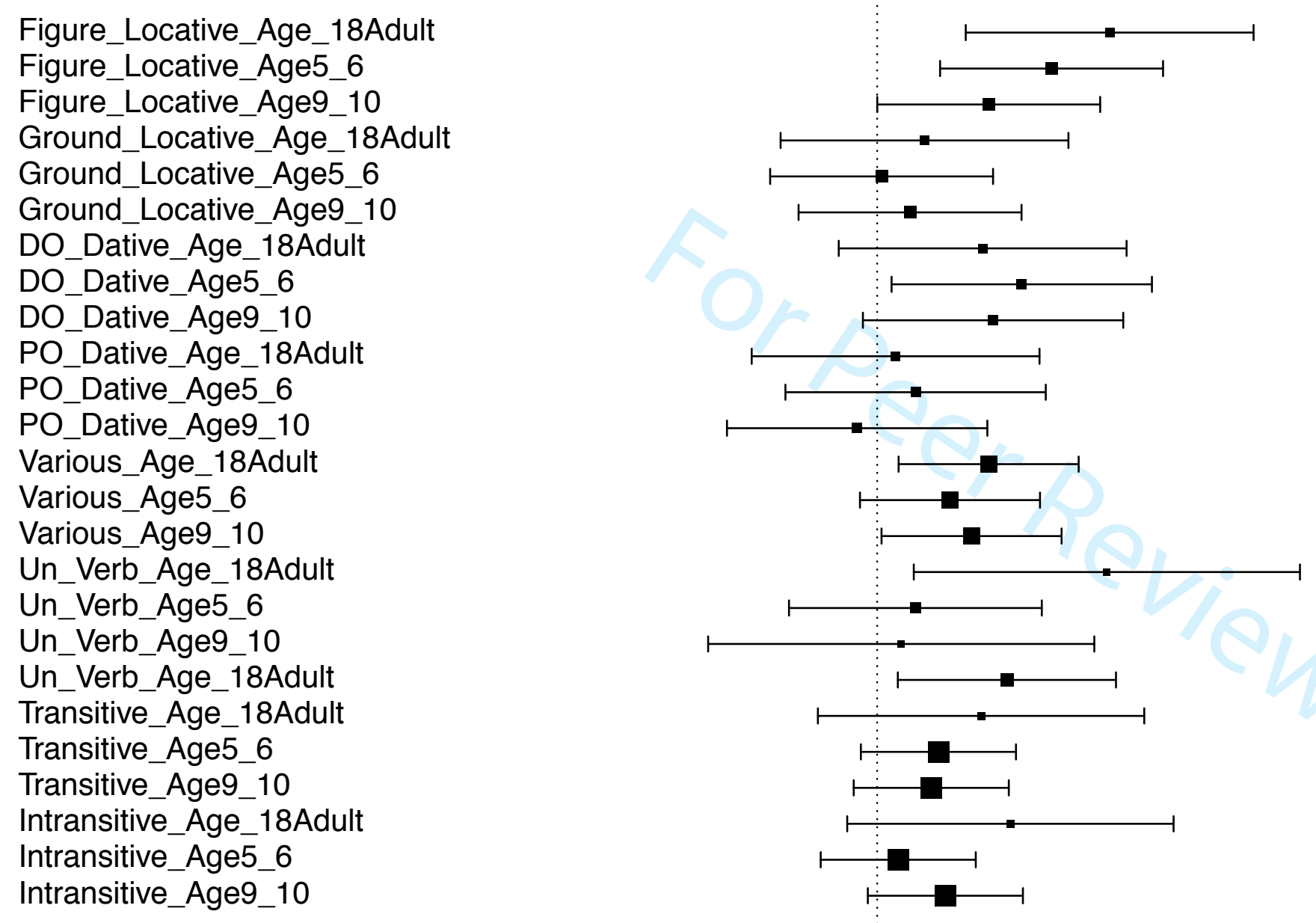
$0.61[0.23,0.99]$
$0.46[0.16,0.75]$
$0.29[0.00,0.58]$
$0.12[-0.25,0.50]$
$0.01[-0.28,0.30]$
$0.09[-0.21,0.38]$
$0.28[-0.10,0.65]$
0.38 [ $0.04,0.72]$
$0.30[-0.04,0.65]$
$0.05[-0.33,0.43]$
$0.10[-0.24,0.44]$
$-0.05[-0.39,0.29]$
0.29 [ $0.06,0.53$
$0.19[-0.05,0.43]$
0.25 [ $0.01,0.48$ ]
$0.60[0.10,1.11]$
$0.10[-0.23,0.43]$
$0.06[-0.44,0.57$
$0.34[0.05,0.63]$
$0.27[-0.16,0.70]$
$0.16[-0.04,0.36]$
$0.14[-0.06,0.35]$
$0.35[-0.08,0.78]$
$0.06[-0.15,0.26]$
$0.18[-0.02,0.38]$

\section{RE Model}

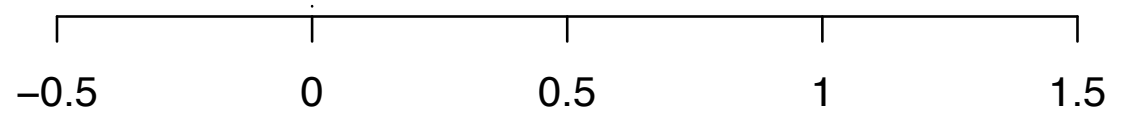

Observed Outcome 


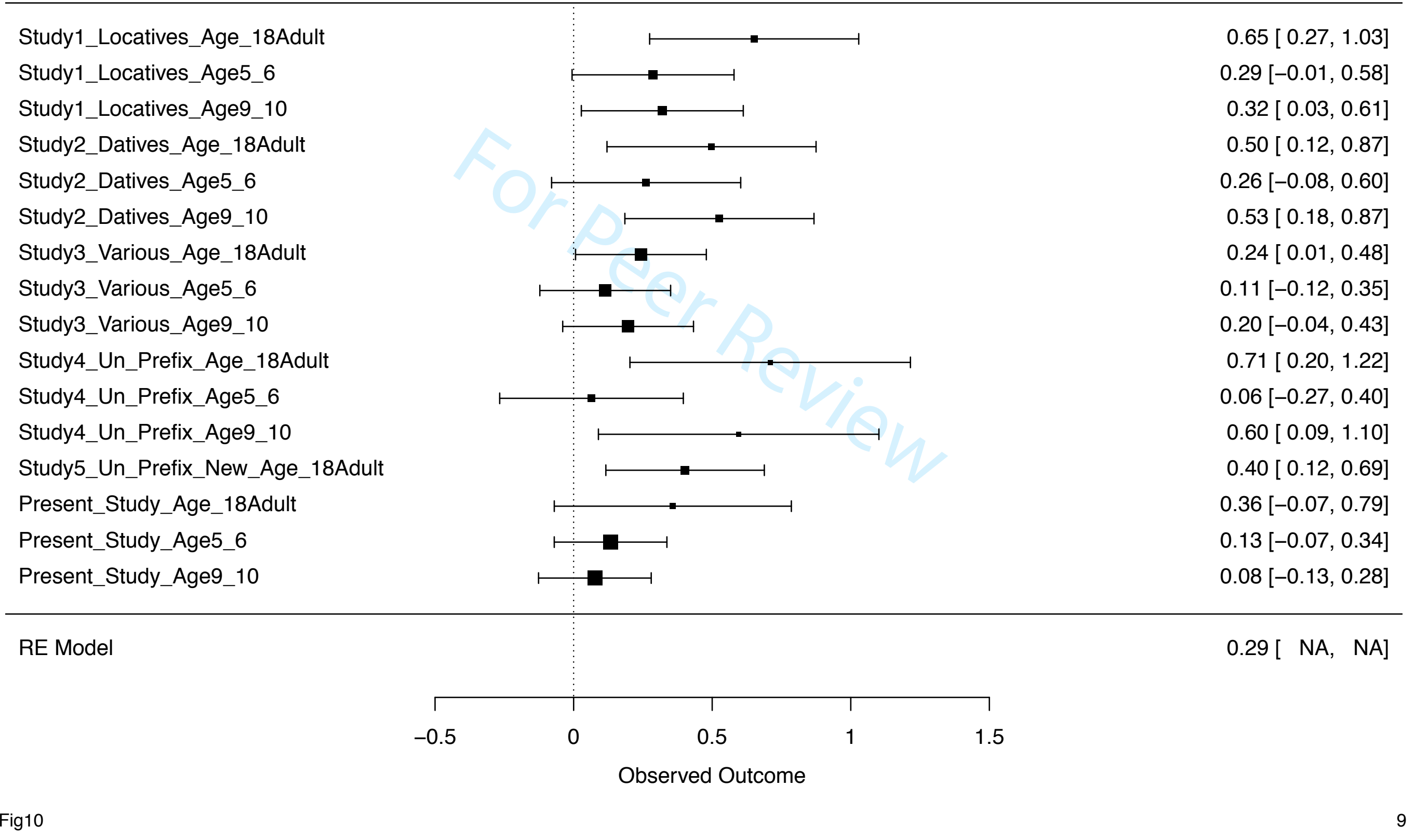




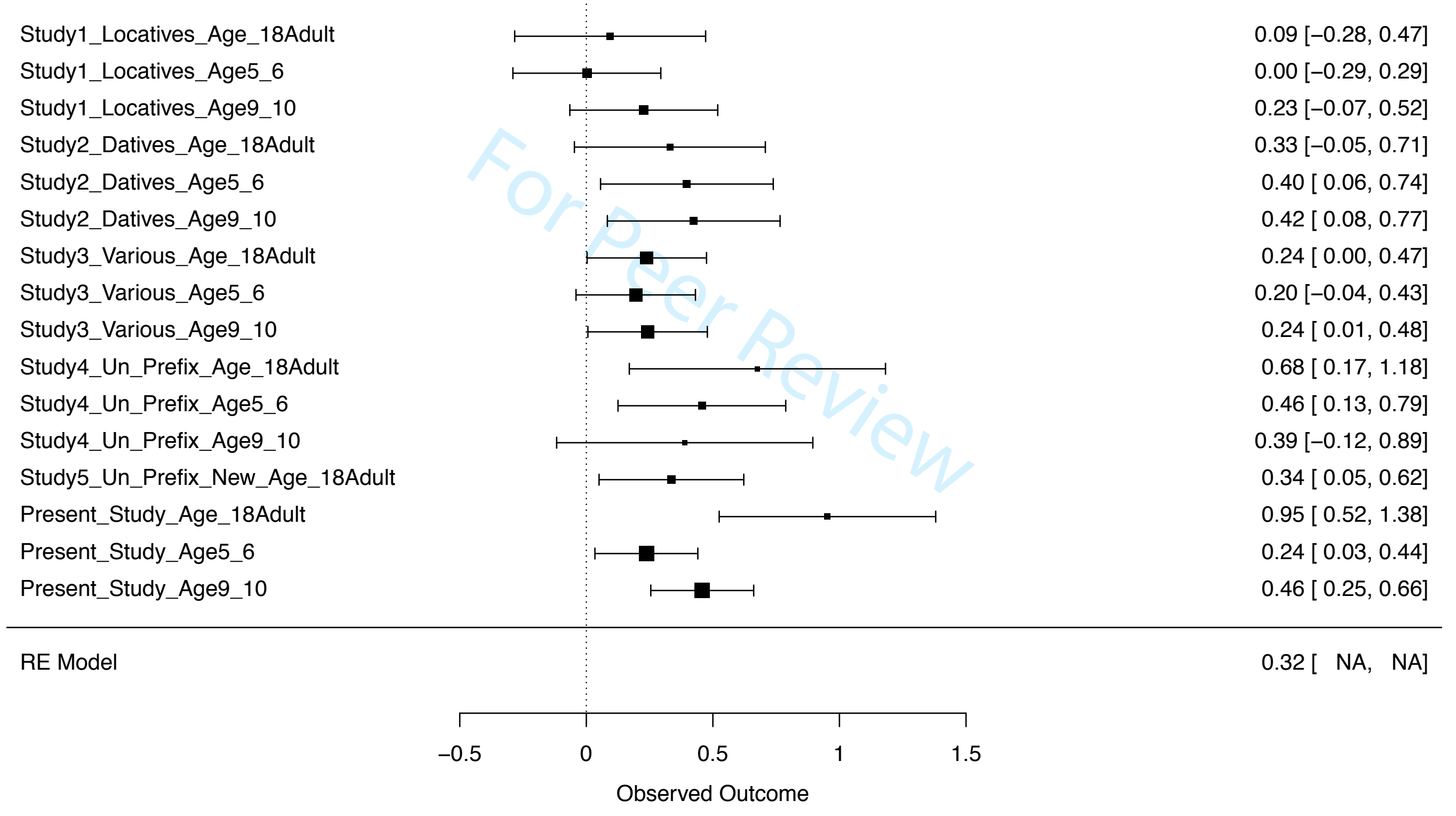




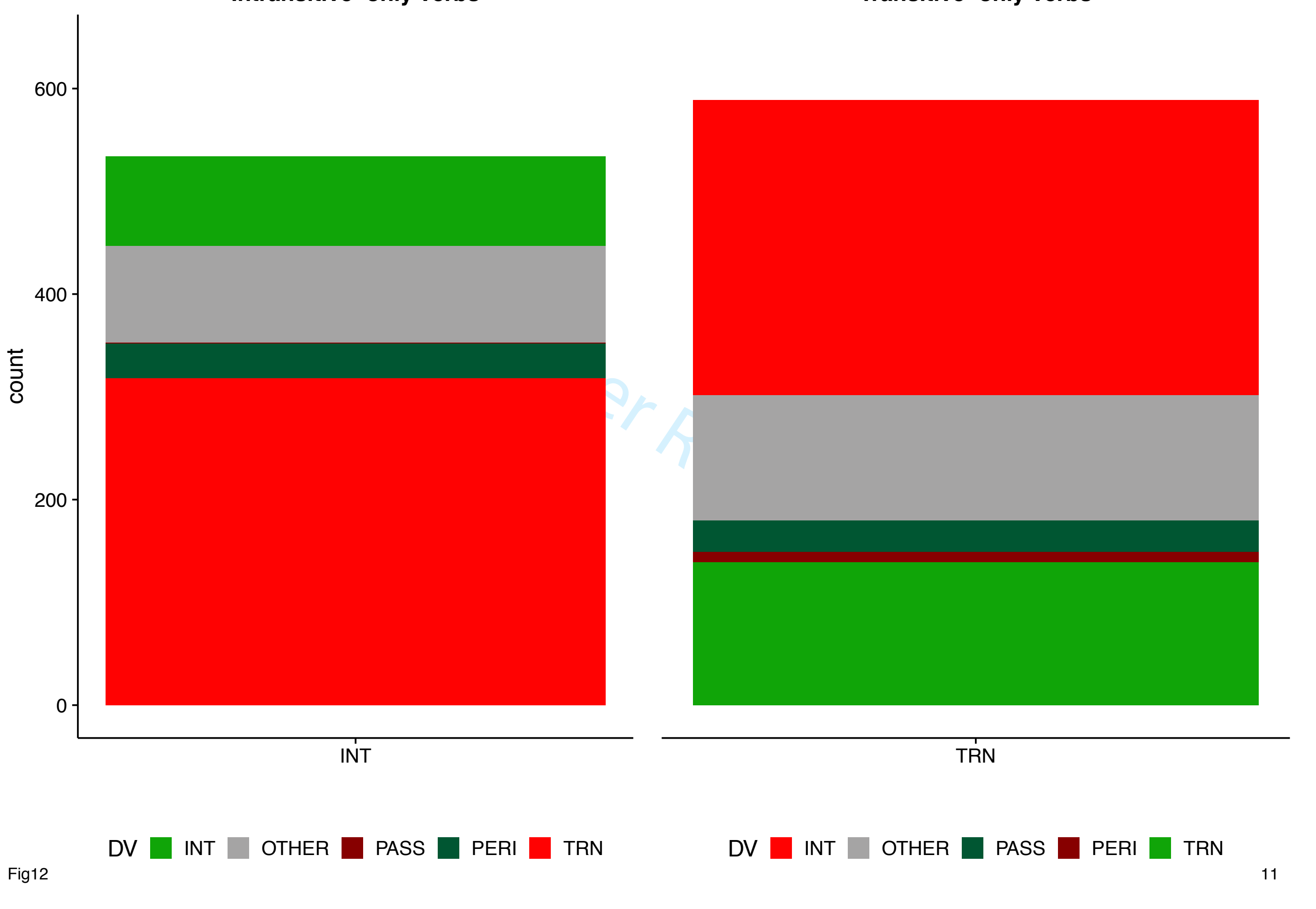


Transitivisation errors $\sim$ Semantics
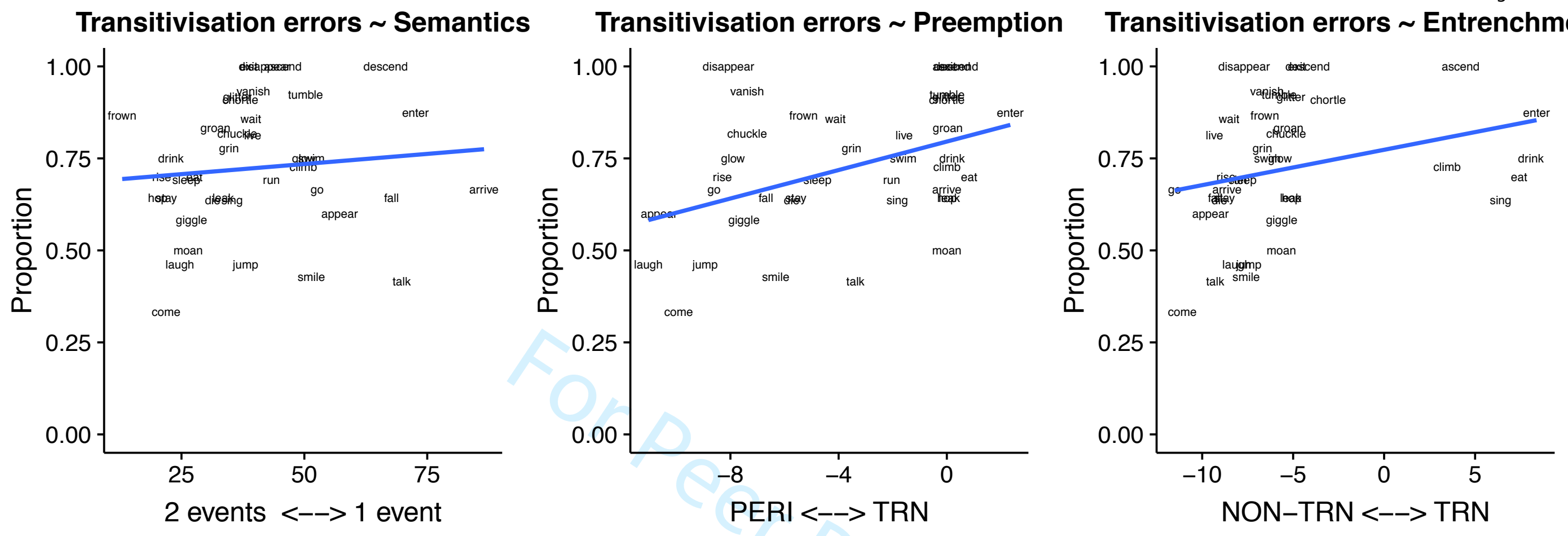

Intransitivisation errors $\sim$ Semantics
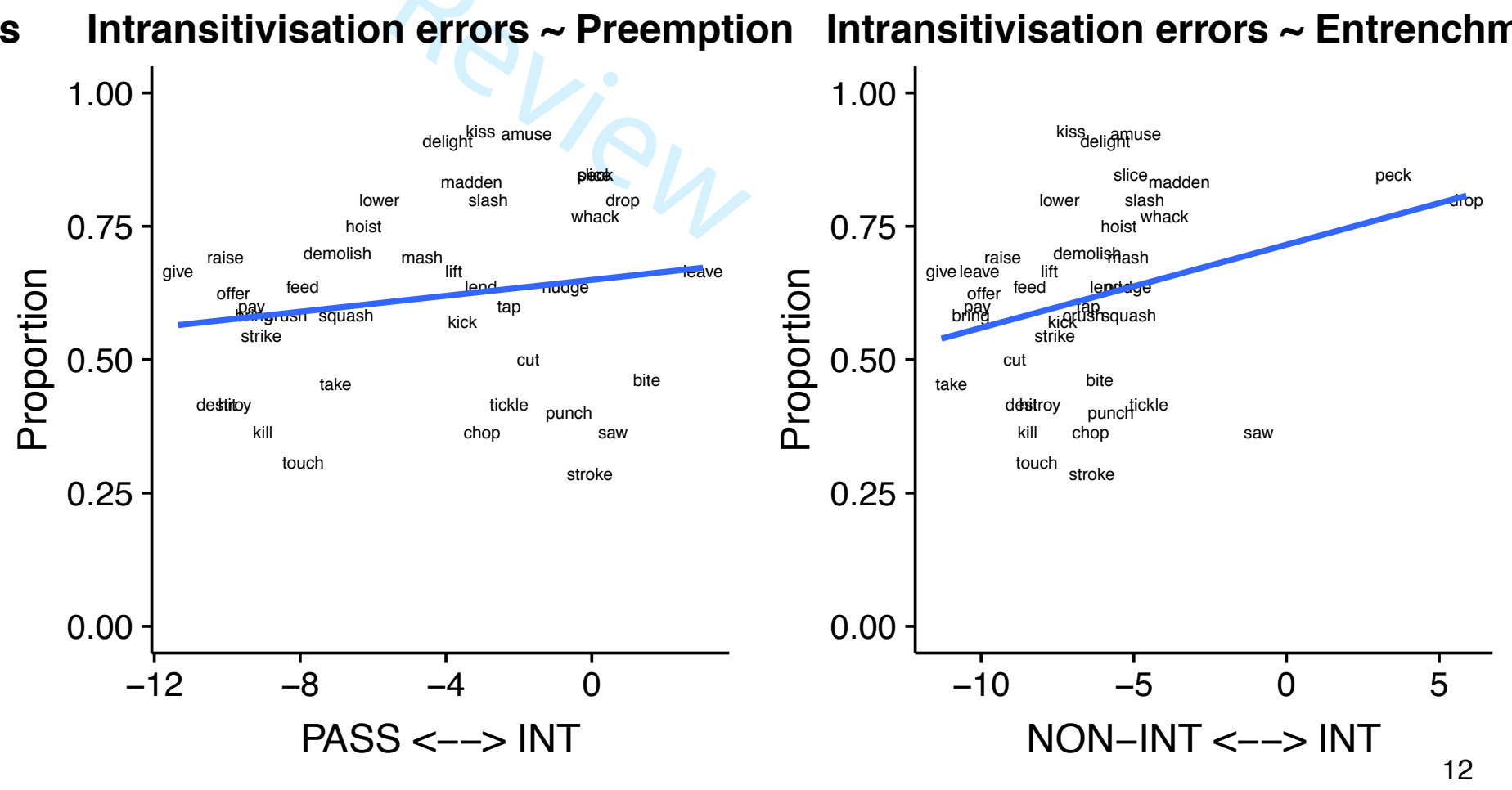


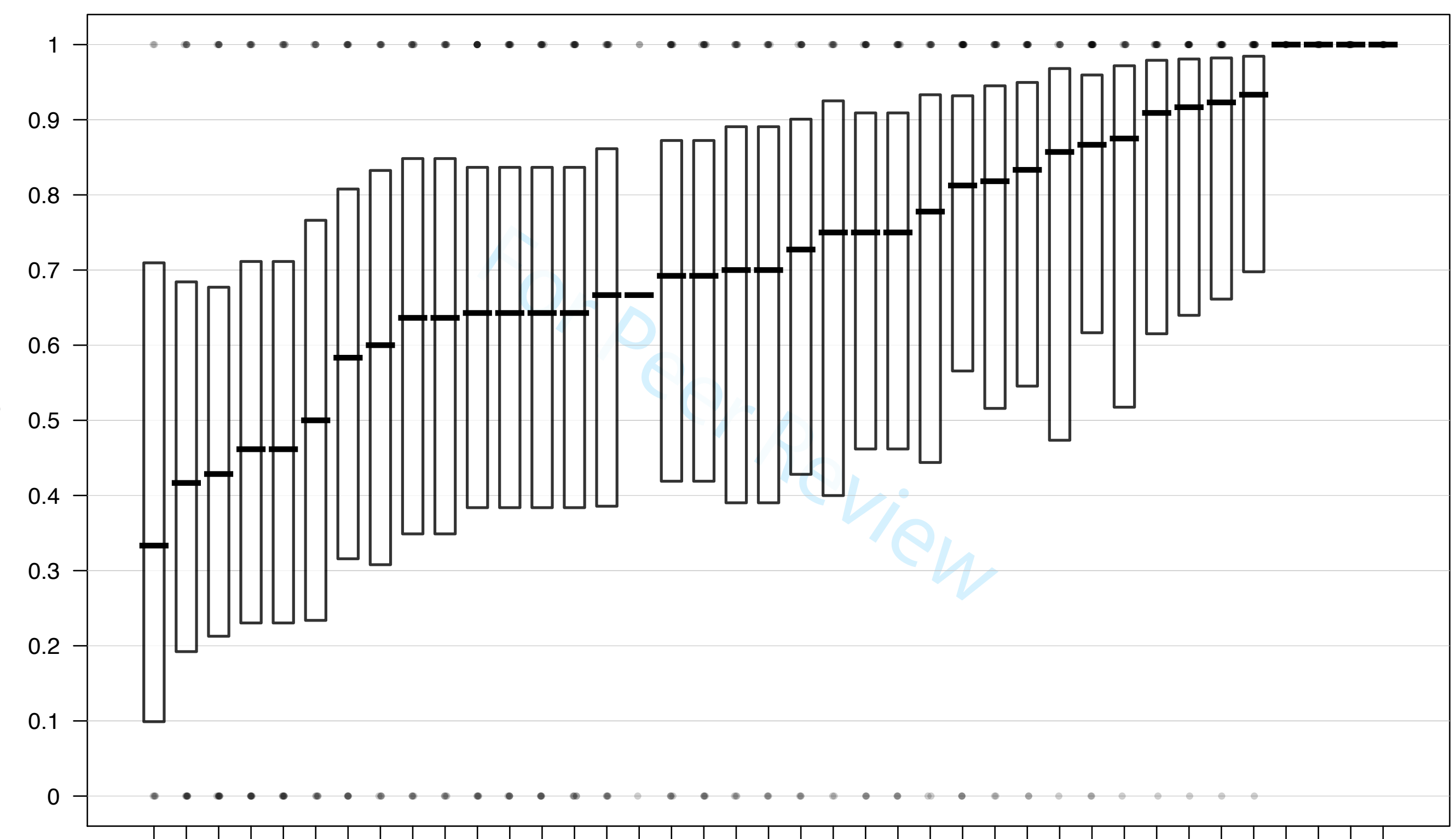

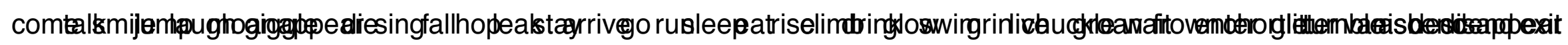

\section{Verb}




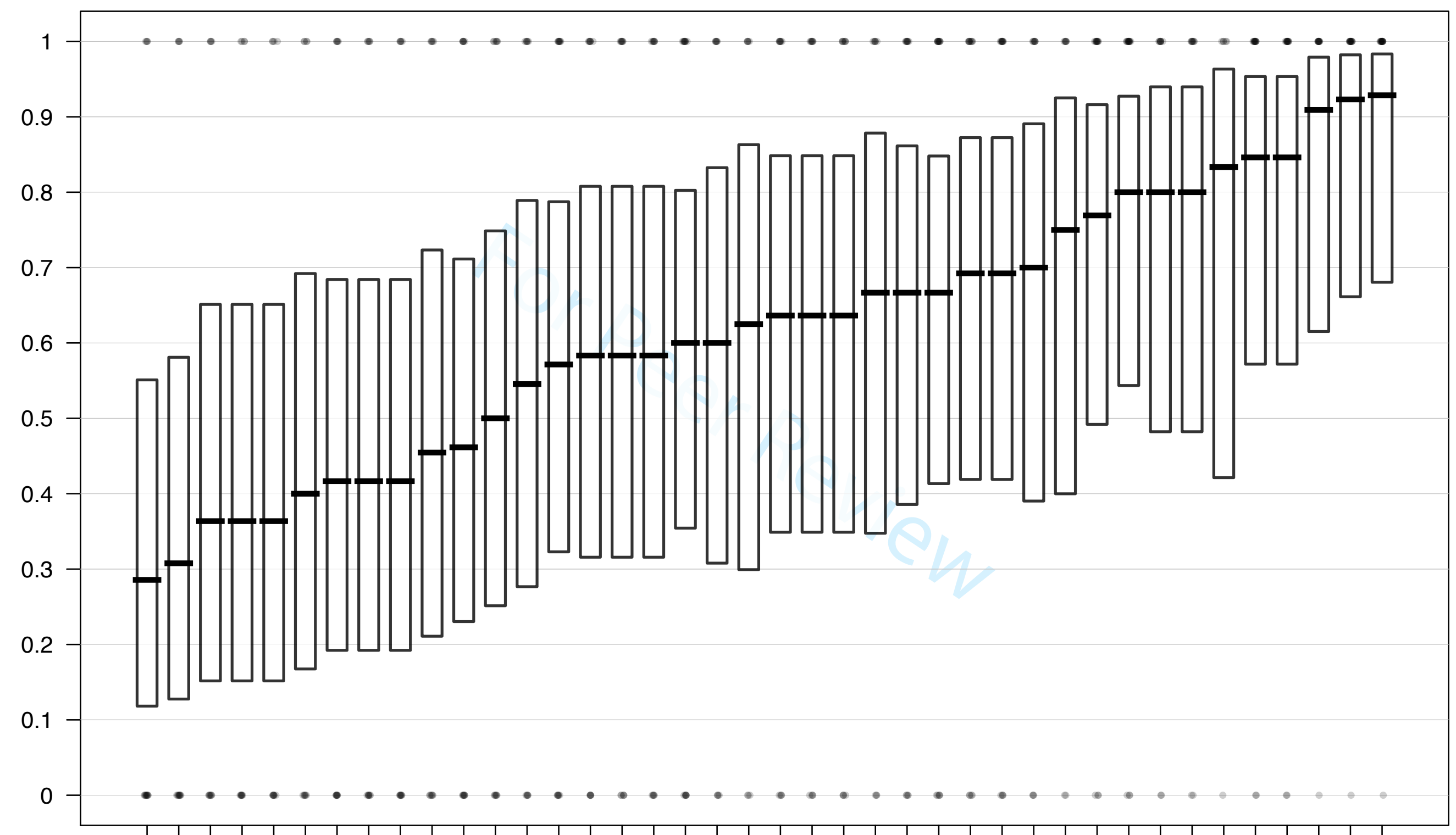

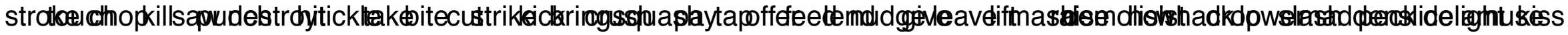


Appendix A. List of all verbs

\begin{tabular}{|c|c|c|}
\hline $\begin{array}{l}\text { Transitive- } \\
\text { only verbs }\end{array}$ & $\begin{array}{l}\text { Intransitive- } \\
\text { only verbs } \\
\end{array}$ & $\begin{array}{l}\text { Alternating } \\
\text { verbs }\end{array}$ \\
\hline cut & go & break \\
\hline slice & come & rip \\
\hline chop & rise & shatter \\
\hline mash & fall & smash \\
\hline hit & tumble & grow \\
\hline strike & ascend & change \\
\hline bite & descend & bake \\
\hline peck & exit & boil \\
\hline touch & enter & cook \\
\hline stroke & arrive & fry \\
\hline slash & eat & burn \\
\hline saw & jump & split \\
\hline crush & hop & tear \\
\hline squash & run & melt \\
\hline kick & drink & crack \\
\hline tap & talk & improve \\
\hline whack & swim & inflate \\
\hline punch & climb & alter \\
\hline nudge & sing & shrink \\
\hline kiss & sleep & freeze \\
\hline kill & smile & crash \\
\hline destroy & cry & fold \\
\hline demolish & laugh & crease \\
\hline take & frown & deflate \\
\hline bring & giggle & defrost \\
\hline raise & chortle & dissolve \\
\hline hoist & chuckle & enlarge \\
\hline lift & grin & expand \\
\hline lower & groan & open \\
\hline leave & moan & close \\
\hline drop & glow & snap \\
\hline tickle & glitter & bend \\
\hline amuse & leak & slide \\
\hline feed & appear & move \\
\hline delight & disappear & roll \\
\hline give & vanish & bounce \\
\hline madden & die & turn \\
\hline lend & stay & begin \\
\hline pay & wait & start \\
\hline offer & live & stop \\
\hline
\end{tabular}

